\title{
Optoelectronic Properties and Nanostructure Formation of $\sigma$-Conjugated Polymers
}

\author{
Shu SEKI ${ }^{\dagger}$ and Seichi TAGAWA \\ The Institute of Scientific and Industrial Research, Osaka University, 8-1 Mihogaoka, Ibaraki, Osaka 567-0047, Japan
}

(Received January 26, 2007; Accepted February 6, 2007; Published March 12, 2007)

\begin{abstract}
This paper reviews recent studies on the opto-electronic properties of $\sigma$-conjugated polymers as well as the nanostructure formation based on the polymeric materials by the single particle nanofabrication technique. The direct quantitative correlation has been found between backbone conformation of $\sigma$-conjugated polymers and delocalization of charge carriers along their conjugated backbones by transient spectroscopy of the ion radicals. The microwave conductivity measurement technique was applied to estimate the intra-chain mobility of the charge carriers, giving the value of isotropic mobility holes along the chains as $c a \cdot 10^{-1} \mathrm{~cm}^{2} \mathrm{~V}^{-1} \mathrm{~s}^{-1}$. This is suggestive that the potentials of rod-like conjugated backbones in polysilanes as 1-D semiconductor are competitive to those of amorphous silicon. Cross-linking reaction of the $\sigma$-conjugated polymers was firstly promoted by charged particle irradiation to the thin films in the present study. Non-homogeneous cross-linking reaction in the polymers gives clear nanowires whose sizes, length, and number density are fairly controlled by selecting particles, molecular weights, etc. We believe that the present technique is applicable to produce wire-like nanostructures based on a variety of polymeric materials via the simple cross-linking reaction schema. [doi:10.1295/polymj.PJ2006222]

KEY WORDS $\sigma$-Conjugated Polymer / Polysilane / Ion Radical / Gel / Nanowire / Microwave Conductivity / Charge Carrier /
\end{abstract}

The $\sigma$-conjugated polymers bearing saturated $\mathrm{Si}$ or Ge backbones are of current interest because of their characteristic electron delocalization along the $\mathrm{Si}$ or Ge chain ${ }^{1}$ and associated opto-electronic properties. ${ }^{2-4}$ The dynamics of excess electrons and holes on the $\mathrm{Si}$ or Ge skeletons have been investigated vigorously in view of their potential application in electro-luminescent diodes and as photo-conductors ${ }^{5,6}$ on the basis of their utility as positive charge conductors. The dominant process of charge carrier transport in $\sigma$-conjugated polymers is the hopping of holes between localized states originating from domain-like subunits along the chain. ${ }^{7,8}$ The mean length of the segments is controlled by steric hindrance of the side chains and/or thermal molecular motion. Several groups have reported the synthesis of a series of polysilanes or polygermanes with backbone conformations varying from random coil to stiff and rod-like by changing the polymer substitution pattern, ${ }^{9-11}$ and the clear correlation between the conformation of the backbones and the characteristic electronic transition observed at nearUV region has been also reported. This is indicative that one can easily estimate the conformation of the $\sigma$-conjugated polymers in solvent at any temperatures by the simple spectroscopy of $\sigma$-conjugated polymer solutions. Despite positive charge being the dominant charge carriers in the transport process, there have been few dynamics or quantitative analyses on the electronic state of positive charges on the $\mathrm{Si}$ or $\mathrm{Ge}$ chain other than by transient spectroscopy ${ }^{12,13}$ or electron spin resonance. ${ }^{14,15}$ Localization of the charge carriers was revealed to be suppressed in the $\sigma$-conjugated polymers bearing bulky pendant groups, suggesting not only that the localization in typical dialkyl substituted polymers arises from the flexibility of $\mathrm{Si}(\mathrm{Ge})$ catenation, but also that delocalization occurs in $\sigma$-conjugated polymers with stiff or rod-like skeletons. However, the quantitative correlation between the molecular stiffness and the degree of positive charge delocalization had not been elucidated to date.

The present review summarizes the recent results on the direct observation of anion and cation radicals of $\sigma$-conjugated polymers by pulse radiolysis. Pulseradiolysis transient absorption spectroscopy (PRTAS) is a very powerful and useful technique for achieving the selective formation of ion radicals in matrices (solvents) and tracing reaction kinetics. To date, quantitative tracing of the anion and cation radicals has been very difficult because of their very low ionization potentials $(<6 \mathrm{eV}){ }^{16,17}$ The PR-TAS is the unique technique to enable the quantitative formation of charged radicals of the polymers without associated counter ions. The intrinsic electronic structures of the charged radicals of the $\sigma$-conjugated polymers includ-

${ }^{\dagger}$ To whom correspondence should be addressed (Tel: +81-6-6879-8502, Fax: +81-6-6876-3287, E-mail: seki@sanken.osaka-u.ac.jp). 
ing the molar extinction coefficient and oscillator strength were determined fully experimentally by both spectroscopic techniques and an efficient charge transfer reaction between the radical ions and some electron acceptors (donors). ${ }^{13,18-22}$ The degree of charge delocalization on $\sigma$-conjugated chains is discussed in terms of the molecular stiffness of $\sigma$-conjugated polymers, and the role of pendant rings in the charge carrier transport processes in polymer materials is addressed.

Based on the spectroscopic measurements on the charged radicals of $\sigma$-conjugated polymers, hence the degree of delocalization excess charges on their skeletons, the intrinsic intra-molecular mobility of the charge carriers along their "stiff" backbones should be higher than that estimated by conventional measurement techniques such as DC time-of-flight (TOF) and/or field effect transistor (FET) measurement. $5,7,23,24$ Generally the DC technique gives the estimates of the speed of charge carriers moving along the direction of the external electric field and traveling the long distance as much as a few $\mu \mathrm{m}$ at least. ${ }^{23,24}$ This is the case giving the relatively lower estimates of charge carrier mobility because of the contribution from hopping between the domain-like subunits as discussed above, trapping at impurities and/or grain boundaries, charge injection delays at the polymerelectrode interfaces, etc.

Pulse-radiolysis time-resolved conductivity (PRTRMC) measurement is a promising technique for examining the potentials of polymer chains as positive or negative charge conductors. ${ }^{25-31}$ The technique has been developed as an electrodeless method of monitoring the conductivity of a material which has been free from the effects due to the electrode interfaces. ${ }^{32-39}$ Recently, the technique was successfully extended to the measurement of conductivity for isolated chains of conjugated polymers in dilute solution, yielding the intrinsic intra-chain conductivity along these chains in the absence of impurities, disordered structures in solids, or inter-molecular hopping processes. ${ }^{26,27,37}$ Both $\pi$-conjugated and $\sigma$-conjugated polymers exhibit remarkably high conductivities compared to the values of the corresponding bulk polymers determined by DC techniques, particularly for polymers bearing stiff backbones. ${ }^{27,40,41}$ Determination of the mobility on the chains, however, requires accurate estimation of the density of charge carriers. The quantitative basis of the radiolytic yield of ionization in the media has been determined with high accuracy in the estimation by a detailed account of kinetic fitting procedure. The TAS and PR-TRMC measurements are combined to elucidate the mobility of charge carriers on isolated $\sigma$-conjugated chains. TAS provides direct information on the number of ion rad- icals of $\sigma$-conjugated polymers formed by electron beam irradiation, leading experimentally to the density of charge carriers in the media. ${ }^{13,19,20,22}$ As the conductivity of the charge carriers can be measured by PR-TRMC, the combination of the two techniques represents a comprehensive approach to determining the intrinsic mobility on isolated $\mathrm{Si}$ chains. ${ }^{27,40}$

The $\sigma$-conjugated polymers have also been focused on as the radiation sensitive polymeric materials since the discovery of the polymers soluble to several organic solvents, because their efficient main chain scission reactions upon exposure to UV light and ionizing radiation was capable to use them as resist materials in the field of micro- and nano-lithography. We have reported the radiation induced reactions in $\sigma$-conjugated polymers and the dependence of reaction processes on the nature of radiation sources: LET (linear energy transfer: energy deposition rate of incident particles per unit length). ${ }^{42-44}$ The polymers seem to be crosslinked by high LET radiations including high energy charged particles, despite of predominant main chain scission reactions observed for low LET radiation. The difference in radiation induced reactions was ascribed to a variation of density of reactive intermediates. The spatial distribution of deposited energy by charged particles played a significant role in promoting chemical reactions in the target materials, ${ }^{45-47}$ and we suggested that the high energy charged particles produced a non-homogeneous field of chemical reactions, where the reactive intermediates produced by an incident ion were radially distributed from the projectile. ${ }^{47,48}$ The size of the field depended on LET, and varied from a few $\mathrm{nm}$ to several tens $\mathrm{nm}$. The non-homogeneous field will give nano-structured materials by high energy charged particles irradiation to polysilane thin films. ${ }^{49-56}$ The present review also demonstrates our recent results on the formation of 1-dimensinal nanostructures by simple ion irradiation to the thin solid films of the $\sigma$-conjugated polymers.

\section{EXPERIMENTAL}

All the monomers of $\sigma$-conjugated polysilanes were synthesized by coupling reaction between Grinard regants of side chains and tetra- or tri-chlorosilanes which were purchased from Sin-Etsu Chemical Co. Ltd. The obtained monomers were distilled twice or crystallized prior to use. Polymerization was carried out by the Kipping method using corresponding R1R2-dichlorosilanes with sodium metal in dry toluene for $5-20 \mathrm{~h}$ at $110{ }^{\circ} \mathrm{C} .{ }^{57}$ The polymer solution was precipitated in several solvents after filtration through a $0.45 \mathrm{~mm}$ PTFE filter to eliminate $\mathrm{NaCl}$, and the precipitates were dried in a vacuum. The toluene solutions of the polymers were transferred into a separato- 


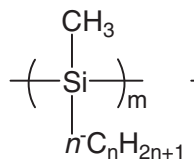

$\operatorname{MEn}(n=3-12)$

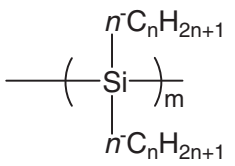

PDn (n=3-12)

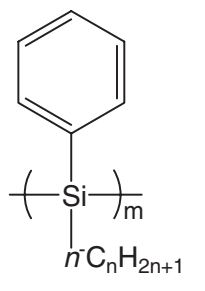

$\mathrm{PHn}(\mathrm{n}=3-12)$<smiles>CC(C)(C)[Si](C)(C)C1CCCCC1</smiles>

PCHMS

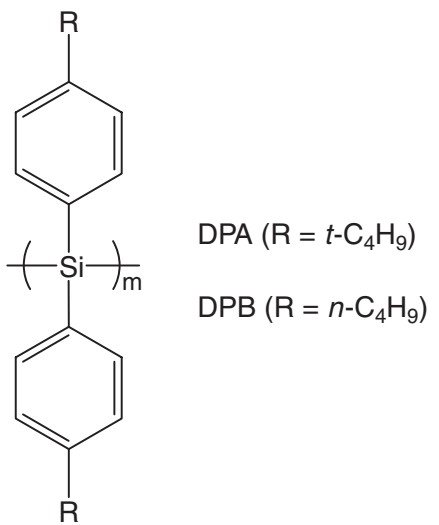

Figure 1. Chemical structure of the series of polysilanes employed.
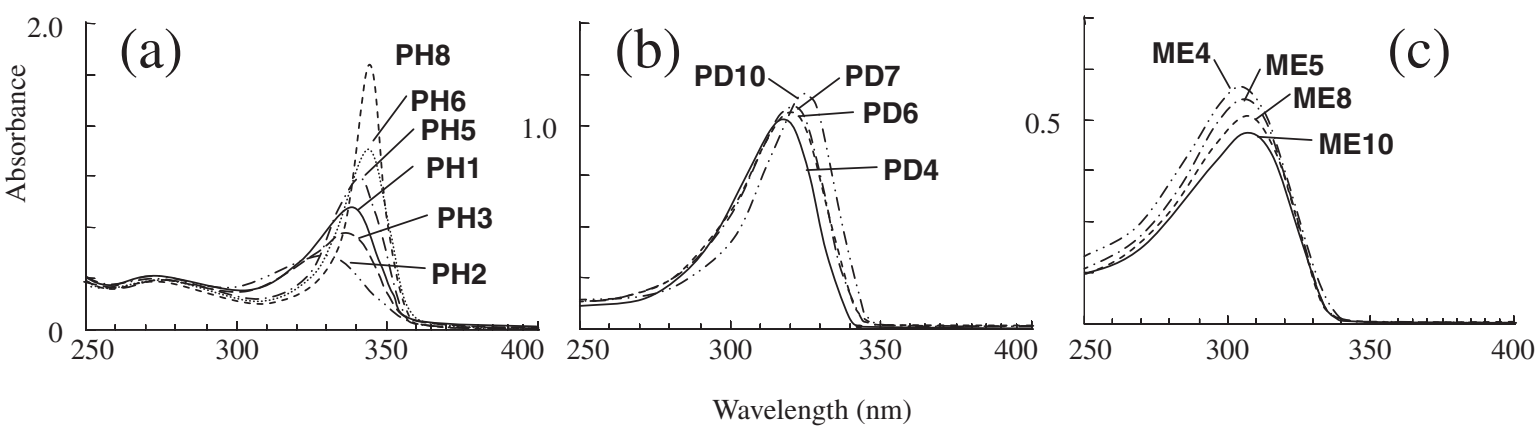

Figure 2. UV-vis absorption spectra of (a) PHn, (b) PDn, and (c) MEn. Spectra were recorded at $25^{\circ} \mathrm{C}$ for solutions of polysilanes in THF at $1.0 \times 10^{-4} \mathrm{~mol} \mathrm{dm}^{-3}$ (base mol unit). Reprinted with permission from S. Seki, et al., J. Am. Chem. Soc., 126, 3521 (2004) (Ref. 13) (C) 2004, American Chemical Society.

ry funnel, washed with water to eliminate remaining $\mathrm{NaCl}$, and precipitated. The polymers were vacuum dried at $80^{\circ} \mathrm{C}$, and precipitated again in several solvent systems. The polymers were fractionally precipitated again to eliminate the lower molecular weight fraction of the bimodal distribution. The synthesis details of monomers and polymers were described elsewhere. ${ }^{13,19}$ The chemical structures of the synthesized polymers are shown in Figure 1. The other experimental details are described in each corresponding section as below.

\section{RESULTS AND DISCUSSIONS}

\section{Electronic Structure of Ion Radicals}

The UV-vis absorption spectra of three series of polysilanes ( $n$-alkylphenyl (PHn), di- $n$-alkyl (PDn), and methyl-n-alkyl (MEn) substituted: the value of $n$ represents the number of carbon atoms in the $n$-alkyl substituents) are shown in Figure 2. The intense UV absorption band observed for steady-state polysilane solutions is ascribed to the transition between the valence band (VB) and the lowest excitonic states (ES) of the Si backbones. ${ }^{58}$ The molar extinction coefficient $\left(\varepsilon^{\text {abs }}\right)$ and oscillator strength $\left(f_{\mathrm{VB}-\mathrm{ES}}\right)$ of the absorption are listed in Table I. The values of both $\varepsilon^{\text {abs }}$ and $f_{\text {VB-ES }}$ depend strongly on the substitution patterns, with a considerable increase accompanying the change from asymmetric alkyl substitution to symmetric alkyl ones. The values also increase dramatically with elongation of $n$-alkyl substituents from methyl to $n$-octyl in the case of poly(n-alkylphenylsilane)s, with only a slight drop with further elongation beyond $n$-octyl. Recently, Fujiki reported an empirical relationship between $\varepsilon^{\text {abs }}$ and the viscosity index $\alpha$, reflecting the geometric structure of the polymer main chain. The following empirical formula was obtained for the relationship between $\alpha$ and $\varepsilon^{\text {abs }}$.

$$
\varepsilon^{\mathrm{abs}}=1130 e^{2.9 \alpha}
$$

The relationship between gyration length $\left(R_{\mathrm{g}}\right)$ and $\alpha$ is as follows:

$$
R_{\mathrm{g}}=\kappa M^{v}
$$

where $\kappa$ is a constant, $M$ is the molecular weight of the polymer, and $v=(\alpha+1) / 3$. The estimated values of $\alpha$ are shown in Figure 3; varying from 0.46 for $\mathrm{PH} 2$ to 0.94 for PH8. Assuming a constant polymerization degree for the polysilanes, $R_{\mathrm{g}}$ is expected to increase with $\varepsilon^{\text {abs }}$. The actual Kuhn segment lengths ( $q$ ) of the polymers were found to be $q=1.1 \mathrm{~nm}$ for PH1 ${ }^{18} 3.0 \mathrm{~nm}$ for PD6, ${ }^{59,60}$ and $4.5 \mathrm{~nm}$ for DPB 
Table I. UV absorption, fluorescence, and optical properties of cation radicals of poly $(n$-alkylphenylsilane $) \mathrm{s}^{\mathrm{a}}$

\begin{tabular}{|c|c|c|c|c|c|c|c|c|c|c|}
\hline Entry & $\begin{array}{l}\lambda_{\max }^{\mathrm{abs}} \\
(\mathrm{nm})\end{array}$ & $\begin{array}{c}\varepsilon^{\text {abs b }} \\
\left(\mathrm{mol}^{-1} \mathrm{dm}^{3} \mathrm{~cm}^{-1}\right)\end{array}$ & $f_{\mathrm{VB}-\mathrm{ES}}^{\mathrm{c}}$ & $\begin{array}{l}\lambda_{\max }^{\mathrm{fl}} \\
(\mathrm{nm})\end{array}$ & $\begin{array}{l}\lambda_{\max }^{\bullet-} \\
(\mathrm{nm})\end{array}$ & $\begin{array}{c}\varepsilon^{\bullet-c} \\
\left(10^{5} \mathrm{~mol}^{-1} \mathrm{dm}^{3} \mathrm{~cm}^{-1}\right)\end{array}$ & $f^{\bullet-}$ & $\begin{array}{l}\lambda_{\max }^{\bullet+} \\
(\mathrm{nm})\end{array}$ & $\begin{array}{c}\mathcal{E}^{\bullet+\mathrm{d}} \\
\left(10^{4} \mathrm{~mol}^{-1} \mathrm{dm}^{3} \mathrm{~cm}^{-1}\right)\end{array}$ & $f^{\bullet+}$ \\
\hline PH1 & 339 & 7900 & 0.091 & 365 & 369 & 1.6 & 0.68 & 365 & 9.4 & 0.49 \\
\hline $\mathrm{PH} 2$ & 331 & 4300 & 0.0547 & 366 & 365 & 1.5 & - & 360 & 6.9 & 0.38 \\
\hline PH3 & 336 & 5700 & 0.0642 & 366 & - & - & - & 363 & 7.1 & 0.42 \\
\hline PH4 & 341 & 8000 & 0.0774 & 366 & 370 & 2.1 & - & 365 & 9.8 & 0.51 \\
\hline PH5 & 342 & 9900 & 0.0914 & 367 & - & - & - & 369 & 12 & 0.59 \\
\hline PH6 & 347 & 11700 & 0.11 & 369 & 370 & 3.0 & - & 372 & 15 & 0.65 \\
\hline PH7 & 348 & 14300 & 0.11 & 369 & - & - & - & 372 & 16 & 0.59 \\
\hline PH8 & 348 & 17500 & 0.13 & 370 & 375 & 3.6 & - & 372 & 18 & 0.63 \\
\hline PH10 & 348 & 16600 & 0.13 & 369 & - & - & - & 370 & 17 & 0.66 \\
\hline PH12 & 348 & 12800 & 0.110 & 369 & - & - & - & 370 & 16 & 0.60 \\
\hline PD4 & 317 & 10400 & 0.053 & 346 & 314 & 1.2 & - & 346 & 4.5 & 0.31 \\
\hline PD5 & 318 & 10400 & 0.056 & 347 & - & - & - & 346 & 4.7 & 0.32 \\
\hline PD6 & 319 & 10600 & 0.056 & 347 & 318 & 1.3 & - & 344 & 5.1 & 0.37 \\
\hline PD7 & 321 & 10900 & 0.057 & 348 & - & - & - & 340 & 5.2 & 0.38 \\
\hline PD8 & 321 & 11600 & 0.057 & 348 & - & - & - & 342 & 5.2 & 0.39 \\
\hline PD10 & 324 & 11700 & 0.057 & 349 & - & - & - & 342 & 5.5 & 0.41 \\
\hline PD12 & 325 & 10600 & 0.050 & 350 & - & - & - & 342 & 5.5 & 0.46 \\
\hline ME3 & 307 & 5200 & 0.043 & 338 & 358 & 1.1 & - & 348 & 3.8 & 0.24 \\
\hline ME4 & 306 & 6400 & 0.045 & 336 & - & - & - & 342 & 4.1 & 0.25 \\
\hline ME5 & 307 & 6100 & 0.045 & 336 & - & - & - & 346 & 4.5 & 0.28 \\
\hline ME6 & 307 & 5600 & 0.043 & 336 & 360 & 1.1 & - & 344 & 5.3 & 0.33 \\
\hline ME8 & 309 & 5500 & 0.041 & 336 & - & - & - & 338 & 4.5 & 0.32 \\
\hline ME10 & 310 & 5300 & 0.040 & 337 & - & - & - & 338 & 3.3 & 0.26 \\
\hline ME12 & 311 & 4700 & 0.034 & 336 & 358 & 0.85 & - & 342 & 3.5 & 0.24 \\
\hline PCHMS & 326 & 7320 & 0.054 & 347 & 366 & 1.3 & - & 355 & 4.9 & 0.33 \\
\hline DPA & 377 & 7600 & 0.0750 & - & 410 & 1.8 & 0.73 & 392 & 17 & 0.65 \\
\hline DPB & 393 & 13300 & 0.11 & - & 405 & 2.4 & 1.9 & $<405$ & $>20$ & $>0.80$ \\
\hline
\end{tabular}

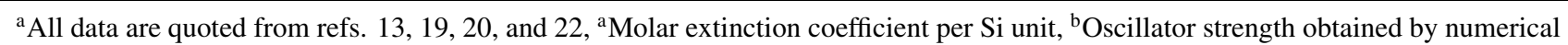
integration, ${ }^{\mathrm{c}}$ Molar extinction coefficient per radical cation at the transient absorption maximum.

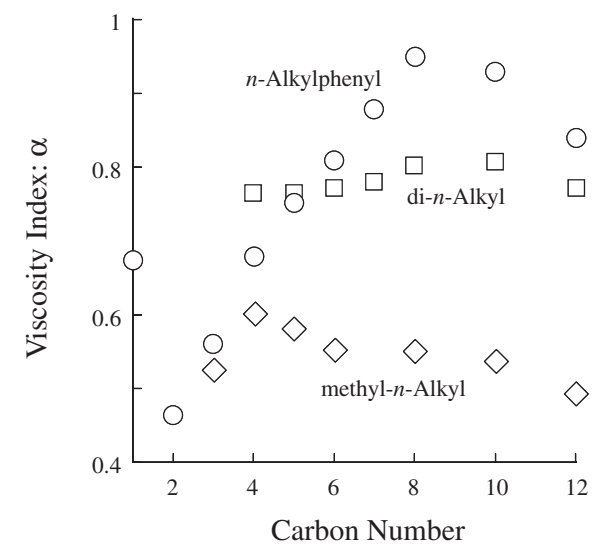

Figure 3. Viscosity index $(\alpha)$ of PHn, PDn, and MEn as a function of length of $n$-alkyl substituents. Values of $\alpha$ are estimated from eq 1 based on $\varepsilon^{\text {abs }}$. Reprinted with permission from S. Seki, et al., J. Am. Chem. Soc., 126, 3521 (2004) (Ref. 13) (C) 2004, American Chemical Society.

determined by light-scattering experiments. ${ }^{18,61}$ All the polysilanes prepared in the present study have high molecular weights $\left(>10^{4}\right)$, low polydispersities $(<4)$, and monomodal distributions similar to the
Schulz-Zimm distribution. The polysilanes with high values of $\alpha$ such as DPB or PH5-PH12, expected to exhibit longer segment length, have molecular weights higher than $10^{5}$. A flexible wormlike chain model with a persistence length of $\sim 10 \mathrm{~nm}$ successfully reproduced the global dimension of the Si chain in DPB with a molecular weight of $\sim 10^{5}{ }^{62}$ Thus, for almost all of the polysilanes in the present study, flexible Kuhn chains are acceptable as the first approximation model of their chain configurations on the basis of $\alpha$ and molecular weight. The gyration length of the flexible Kuhn chain is given by

$$
R_{\mathrm{g}}=\left(\frac{\left\langle r^{2}\right\rangle_{0}}{6}\right)^{1 / 2}
$$

where $\left\langle r^{2}\right\rangle_{0}$ is the mean-square end-to-end distance under $\theta$ conditions. The value of $q$ at the chosen molecular weight is derived from the mean-square endto-end distance $\left(\left\langle r^{2}\right\rangle\right)$ as follows.

$$
q=\left\langle r^{2}\right\rangle\left(\frac{M_{L}}{2 M}\right)
$$

where $M_{L}$ is the mass per unit length. The excluded 
volume parameter $a$ is defined as $a^{2} \equiv\left\langle r^{2}\right\rangle /\left\langle r^{2}\right\rangle_{0}$, and has been reported to be less than 1.2 for DPB at $25^{\circ} \mathrm{C}$ in toluene, which is a better solvent than THF. ${ }^{60}$ The low second virial coefficient of PD6 in THF $\left(1.14 \times 10^{-4} \mathrm{~mL} \mathrm{~mol} / \mathrm{g}^{2}\right)$ also supports the small contributions of exclude volume effects on the conformations of polysilanes with longer segment lengths than PD6. ${ }^{59,60}$ Thus, the assumption of $a=1$ gives an appropriate estimate of the segment length for DPB, PH5-PH12 and PD6-PD12, although the segment length of polysilanes with highly flexible backbones may be underestimated. On the basis of the $\mathrm{Si}-\mathrm{Si}$ bond length $(0.2414 \mathrm{~nm})$ and $\mathrm{Si}-\mathrm{Si}-\mathrm{Si}$ bond angle $\left(114.4^{\circ}\right),{ }^{63}$ the estimated Kuhn segment length varies from 0.55 to $8.6 \mathrm{~nm}(\mathrm{PH} 2-\mathrm{PH} 8)$ for the poly $(n$-alkylphenylsilane)s, $0.48-1.1 \mathrm{~nm}$ (ME3-ME10) for the poly(methyl- $n$-alkylsilane)s, and $2.4-6.3 \mathrm{~nm}$ (PD4PD12) for the poly(di- $n$-alkylsilane)s.

The segment length also reflects the degree of delocalization of the lowest excitonic state along the Si chains, and is described by the following empirical relationship. ${ }^{9,18,64}$

$$
\varepsilon^{\mathrm{abs}}=330 L
$$

where $L$ is the segment length in $\mathrm{Si}$ repeating numbers. Eq 5 gives a shortest value of $L \cong 13$ for $\mathrm{PH} 2$ and a longest value of $L \cong \sim 53$ for PH8 in the present study, consistent with the changes in $f_{\mathrm{VB}-\mathrm{ES}}$.

In the pulse-radiolysis experiment, the incident electron pulse in the solution produces cation radicals $\left(\mathrm{Bz}^{\bullet+}\right)$, excited states $\left(\mathrm{Bz}^{*}\right)$, and electrons, as follows.

$$
B z \rightarrow B z^{\bullet+}, B z^{*}, e^{-}
$$

In deaerated solutions containing triethylamine (TEA), $\mathrm{Bz}^{\bullet+}$ is scavenged by TEA and the excess electrons react with polysilane molecules (PS) according to

$$
\begin{aligned}
& B z^{\bullet+}+T E A \longrightarrow[B z \cdots T E A]^{\bullet+} \\
& e^{-}+P S \underset{k_{1}}{\longrightarrow} P S^{\bullet-},
\end{aligned}
$$

giving polysilane anion radicals $\left(\mathrm{PS}^{\bullet+}\right)$ without contribution from counter cations. The excited states and excess electrons are rapidly scavenged in oxygensaturated solutions $\left(\left[\mathrm{O}_{2}\right]=11.9 \mathrm{mM}\right.$ at $\left.1 \mathrm{~atm}, 25^{\circ} \mathrm{C}\right)$ giving singlet oxygen molecules $\left({ }^{1} \mathrm{O}_{2}\right)$ and oxygen anions $\left(\mathrm{O}_{2}^{-}\right) \cdot{ }^{22,27,65}$ PS in the solution react with $\mathrm{Bz}^{\bullet+}$ via $\mathrm{Bz}_{2}{ }^{\bullet+}$, yielding polymer cation radicals $\left(\mathrm{PS}^{\bullet+}\right)$ :

$$
B z_{2}{ }^{\bullet+}+P S \underset{k_{2}}{\longrightarrow} 2 B z+P S^{\bullet+}
$$

The present authors have already discussed the transient spectra of radical ions of polysilanes including PH1, PD6, etc. ${ }^{12,13,15,18-22,66} \mathrm{PS}^{\bullet-}$ and $\mathrm{PS}^{\bullet+}$ were found to exhibit two absorption bands in the near-UV
$(350-400 \mathrm{~nm})$ and infrared (IR; > $1600 \mathrm{~nm})$ regions. The transient spectra of $\mathrm{PS}^{\bullet-}$ and $\mathrm{PS}^{\bullet+}$ suggest the presence of an interband level occupied by an excess electrons $\left(\mathrm{IBL}^{-}\right)$or by a hole $\left(\mathrm{IBL}^{+}\right)$. The UV and IR bands in $\mathrm{PS}^{\bullet-}$ are due to transition from the valence band (VB) to $\mathrm{IBL}^{-}$, and from $\mathrm{IBL}^{-}$to the conduction band (CB), respectively. This is also the case of PS ${ }^{\bullet+}$, attributing the UV and IR bands to transition from $\mathrm{IBL}^{+}$to the conduction band (CB), and from the valence band $(\mathrm{VB})$ to $\mathrm{IBL}^{+}$, respectively. The presence of $\mathrm{IBL}^{-}$or $\mathrm{IBL}^{+}$is well interpreted as a delocalized negative (positive) polaron state $13,19,23,67,68$ and/or Anderson localization state on an $\mathrm{Si}$ segment. ${ }^{69,70}$ Figure 4 shows a series of transient absorption spectra of anion radicals observed in PH1-12 as the examples of the transient absorption spectra. The spectra observed for anion radicals of MEn and PDn are almost identical, with only a small dependence on the chain length of $n$-alkyl substituents. In contrast, PHn, in Figure 4, exhibit dramatic changes in the IR band with a considerable red shift upon elongation of the $n$-alkyl chains. The IR band of cation radicals of PHn also tend to shift dramatically with an elongation of $n$-alkyl substituents, despite of negligible small change observed for the IR bands of MEn and PDn anion radicals. ${ }^{20}$ The peak energy of the IR band in relation to the binding energy of negative or positive polarons on the Si chains ${ }^{19,71}$ is given by

$$
\delta \varepsilon \approx\left(\frac{\Delta V}{2 A}\right)\left(\frac{a}{\zeta_{\mathrm{p}}}\right)^{2}
$$

where $\delta \varepsilon$ denotes the binding energy of a polaron, $a$ denotes a lattice unit of a trans-chain segment, and $\xi_{\mathrm{p}}$ is the polaron width. $V$ is the matrix element describing the interaction between two atomic orbitals consisting of a covalent bond, and $\Delta$ denotes the matrix element between two atomic orbitals of an $\mathrm{Si}$ atom. The parameter $A$ is given by

$$
\begin{aligned}
A & \equiv[V(l)-\Delta] \\
l & =\frac{a}{\sin \theta}
\end{aligned}
$$

where $2 \theta$ is the tetrahedral bond angle. Thus, $\Delta$ is a parameter specifying the degree of delocalization of $\sigma$ electrons on a $\sigma$-conjugated segment, while $V$ describes the localization of a pair electrons in a local bond. The relative polaron width on the polymers can be estimated based on eq 8 . With the previously reported values of $\Delta$ in poly(dimethylsilane) $)^{72,73}$ and $V$ in poly(dichlorosilane), ${ }^{63}$ the value of $(\Delta V / 2 A)$ can be estimated to be $c a .1 .6 \mathrm{eV}$. The transition energy of the IR band observed for $\mathrm{PH} 2$ cation radicals is $0.77 \mathrm{eV}$, the highest example value for all the polysilanes, yielding $\xi_{\mathrm{p}}=\sim 2 \mathrm{Si}$ repeating units as the minimum value. The considerable red shift of the IR 

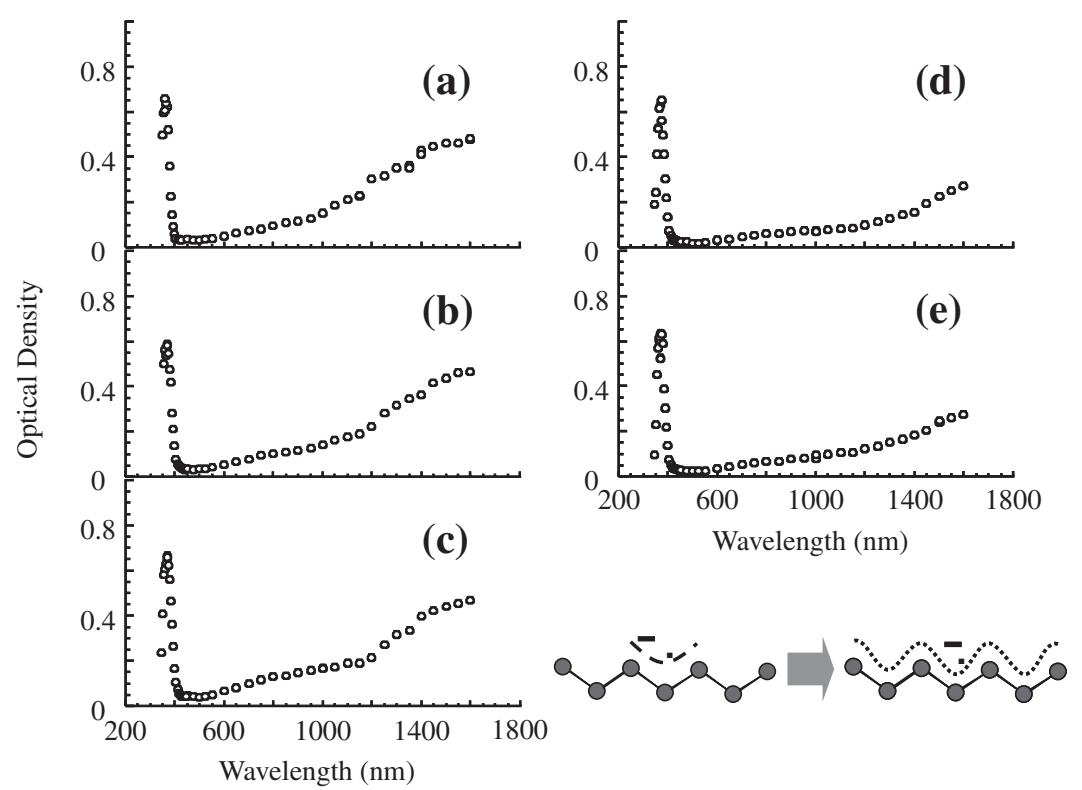

Figure 4. Transient absorption spectra of anion radicals of (a) $\mathrm{PH} 1$, (b) $\mathrm{PH} 2$, (c) $\mathrm{PH} 4$, (d) $\mathrm{PH} 6$, and (e) $\mathrm{PH} 8$, in $\mathrm{Bz}$ at $5.0 \times 10^{-3}$ mol dm ${ }^{-3}$ (base mol unit) with trietylamine at RT, $2.0 \times 10^{-2} \mathrm{~mol} \mathrm{dm}^{-3}$ conc. Spectra were recorded $10 \mathrm{~ns}$ after electron pulse irradiation.

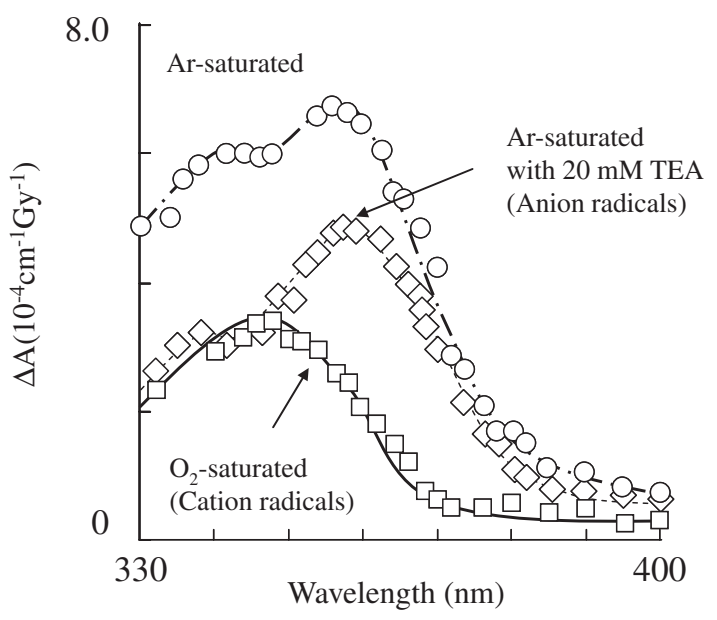

Figure 5. UV band in the transient absorption spectra of ME3 in $\mathrm{Bz}$ at $5.0 \times 10^{-3} \mathrm{~mol} \mathrm{dm}^{-3}$ (base mol unit). Spectra were recorded $100 \mathrm{~ns}$ after electron pulse irradiation. Solid (squares), dashed (diamonds), and dot-dashed (circles) lines are spectra observed in $\mathrm{O}_{2}$-saturated, Ar-saturated with TEA at $2.0 \times 10^{-3}$ mol dm ${ }^{-3}$, and Ar-saturated solutions, respectively. Reprinted with permission from S. Seki, et al., J. Am. Chem. Soc., 126, 3521 (2004) (Ref. 13) C 2004, American Chemical Society.

band observed for PHn induces a dramatic increase in the polaron width, and hence a highly delocalized negative (anion radicals) or positive (cation radicals) charge state.

Figure 5 shows the transient UV band observed for the ME3 solution. The spectra appear to suggest the simultaneous formation of the radical anion and cation in the Ar-saturated solution, leading to overlap of the two transient absorption bands at $358 \mathrm{~nm}$ and $348 \mathrm{~nm}$, which have been determined independently. ${ }^{13,21,22} \mathrm{In}$ contrast to the Ar-saturated solution, only the radical anion or the radical cation is selectively formed in the Ar-saturated solution with $20 \mathrm{mM}$ triethylamine (TEA) or the $\mathrm{O}_{2}$-saturated solution. The kinetic trace is recorded over a wide range of observation time from a few ns to $\mu$ s. The extinction coefficients of anion radicals were also determined by an use of the electron transfer reaction between PS and pyrene (Py) as follows:

$$
P S^{\bullet-}+P y \longrightarrow P S+P y^{\bullet-}
$$

The kinetic traces of $\mathrm{PS}^{\bullet-}$ and $\mathrm{Py}^{\bullet-}\left(\varepsilon^{\bullet-}=5.0 \times\right.$ $10^{4} \mathrm{M}^{-1} \mathrm{~cm}^{-1}$ at $492 \mathrm{~nm}^{74}$ ) gave the $\varepsilon^{\bullet-}$ values of polysilanes as summarized in Table I. The extinction coefficient of the cation radicals can also be determined by the charge transfer reaction between $\mathrm{PS}^{\bullet+}$ and $N, N, N^{\prime}, N^{\prime}$-tetramethyl-p-phenylene-diamine (TMPD) as follows.

$$
P S^{\bullet+}+T M P D \longrightarrow P S+T M P D^{\bullet+}
$$

The formation process of TMPD ${ }^{\bullet+}$ can be observed as an increasing process in the transient absorption at $570 \mathrm{~nm}$, at which $\mathrm{TMPD}^{\circ}+$ in Bz peaks with an extinction coefficient of $1.2 \times 10^{4} \mathrm{M}^{-1} \mathrm{~cm}^{-1}$. ${ }^{75}$ The fitting of the formation kinetic trace at $570 \mathrm{~nm}$ and the decay trace at the absorption maximum of $\mathrm{PS}^{\bullet+}$ based on the extinction coefficient of TMPD ${ }^{\bullet+}$ gives $\mathrm{PS}^{\bullet+}$ extinction coefficients $\left(\varepsilon^{\bullet+}\right)$ of $3.3 \times 10^{4}$ to $2.0 \times$ $10^{5} \mathrm{M}^{-1} \mathrm{~cm}^{-1}$, as listed in Table I.

In the quantitative elucidation of the degree of charge delocalization on the Si skeleton, the authors have already reported the degree of charge delocalization $\left(n_{\text {del }}\right)$ determined through simultaneous observa- 


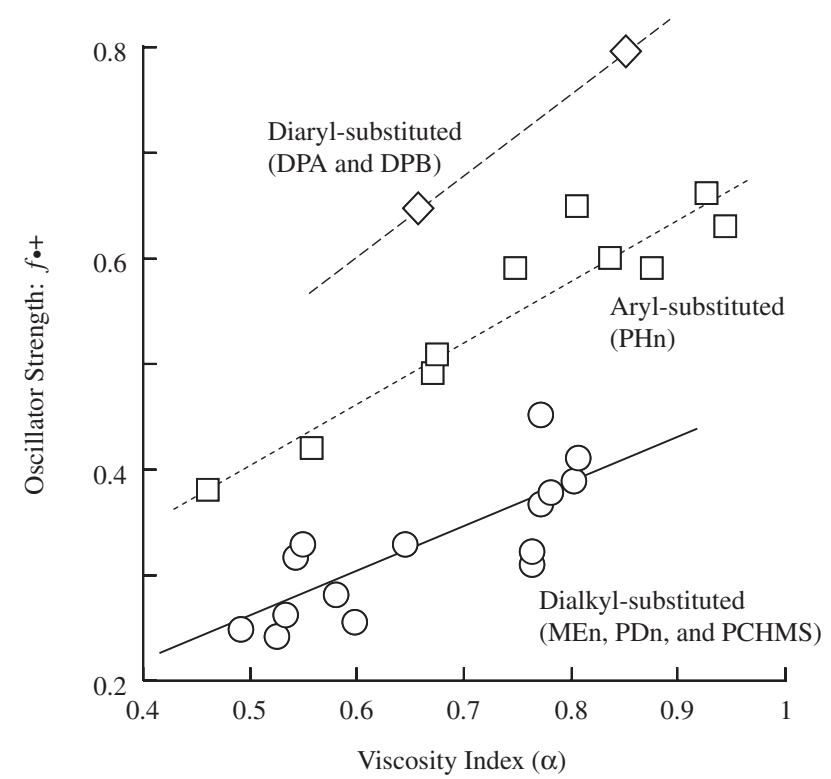

Figure 6. Oscillator strength $\left(f^{\bullet+}\right)$ of UV band $v$ s. viscosity index $(\alpha)$. Reprinted with permission from S. Seki, et al., J. Am. Chem. Soc., 126, 3521 (2004) (Ref. 13) (C)2004, American Chemical Society.

tion of the transient bleaching of the lowest excitonic backbone peak $\left(\triangle^{B l} O D\right)$ and the formation of the UV bands $\left(\Delta^{\bullet \pm} O D\right)$, as given by ${ }^{13,20,22}$

$$
n_{\mathrm{del}}=\frac{\Delta_{O D}^{B l} \cdot \varepsilon^{\bullet \pm}}{\Delta_{O D}^{\bullet \pm} \cdot \varepsilon_{E S}}
$$

The empirical relationship between the apparent oscillator strength of the UV band $\left(f^{\bullet \pm}\right)$ and the value of $n_{\text {del }}$ has also been obtained, expressed as ${ }^{13,19-21}$

$$
\begin{aligned}
& n_{\text {del }} \propto f^{\bullet \pm} \\
& f^{\bullet \pm}=4.32 \times 10^{-9} \int \varepsilon^{\bullet \pm} \mathrm{d} v
\end{aligned}
$$

The values of $f^{\bullet-}$ and $f^{\bullet+}$ can be obtained by numerical integration of the Gaussian fit to the $\mathrm{IBL}^{+}$CB transitions. The obtained values of $f^{\bullet-}$ and $f^{\bullet+}$ are also summarized in Table I. The half-Gaussian (high-energy side), half-Lorentzian (low-energy side) fit gives lower values of $f^{\bullet-}$ and $f^{\bullet+}$, but the difference between the two fittings is less than $20 \%$ for all spectra. The values of $f^{\bullet+}$ for a series of MEn, PDn, $\mathrm{PHn}$, and poly(arylsilane)s are plotted as a function of $\alpha$ in Figure 6. The values of $\varepsilon^{\bullet+}$ principally reflect the values of $\alpha$, and exhibit a similar dependence on the degree of delocalization of excitonic states on the Si backbone. However, $\varepsilon^{\bullet+}$ and $f^{\bullet+}$ values observed for the phenyl-substituted polysilanes are clearly higher than those for the dialkyl-substituted polysilanes. In contrast to cation radicals, the anion radicals of all the polysilanes represent clear correlation between the values of $f^{\bullet-}$ and $\alpha$, without contribution from the presence of phenyl pendant groups in their side chains.
The values of both $q$ and $L$ derived from eqs 4 and 5 clearly indicate that the physical segmentation length in $\mathrm{Si}$ backbones of the ground-state or excited-state polysilanes is well interpreted in terms of molecular stiffness $\alpha$. In the case of cation radicals, the dependence of $f^{\bullet+}$, or $n_{\text {del }}$, on molecular stiffness can be apparently categorized into three series: polysilanes bearing no, one, or two phenyl rings, despite of no categories presenting in anion radicals. It should be noted that the transient spectra in the present study were recorded after intra-chain charge transfer processes, which were expected to occur within a few $\mathrm{ns},{ }^{76}$ thus the spectra are mainly due to energetically favorable segments in polysilane backbones. Despite the fact that PH2 exhibit almost identical Stokes shifts to those of any poly(dialkylsilane)s, a relatively high value of $f^{\bullet+}$ is observed for $\mathrm{PH} 2$. This is strongly suggestive of a crucial contribution from the phenyl rings only in the delocalization of positive charges. Takeda et al. suggested, based on theoretical calculations, that the valence and excitonic states of steady-state polysilanes bearing phenyl rings are considerably affected by $\sigma-\pi$ mixing. ${ }^{44}$ The present results also indicate that this is the case, giving rise to $\mathrm{IBL}^{+}$. A delocalized $\mathrm{IBL}^{+}$over the phenyl ring is a good explanation for the increase in $f^{\bullet+}$ for $\operatorname{poly}(n$-alkylphenylsilane), though a $\mathrm{IBL}^{-}$is considered to be localized onto $\mathrm{Si}$ chains without spreading over phenyl substituents. This explanation is supported by models of the spread of the singly occupied molecular orbital (SOMO) state into substituents, as calculated theoretically only for polysilane cation radicals. ${ }^{14,18,19}$ Therefore, the UV band includes both the transition from $\mathrm{IBL}^{+}$to the $\mathrm{CB}$, and the transition from $\mathrm{IBL}^{+}$to pseudo- $\pi$ at an energy of $\sim 0.2 \mathrm{eV}$ below the $\mathrm{CB}$.

\section{Intrinsic Mobility of Charge Carriers along $\sigma$-Conju- gated Chains}

In this section, the intrinsic mobility of charge carriers along $\sigma$-conjugated chains with different backbone conformations and length is discussed by means of TRMC technique. Fractional precipitation and centrifugal separation of PH1 and PH6 gave the polymer lots of a variety of molecular weights, and each 5 entries (PH1-1 5 and PH6-1 5) with small molecular weight distributions were selected for an use in the present study. The absorption and fluorescence maxima of all PH1-1 5 were almost identical despite almost up to two orders of magnitude difference in molecular weight. The $\varepsilon^{\mathrm{abs}}$ of the PH1 increased slightly with molecular weight. The empirical relationship between $\varepsilon^{\text {abs }}$ and the mean degree of delocalization of the lowest excitonic state on the Si backbone was already discussed in the previous section represented as eq $5 .^{9,13,18,64} \mathrm{Eq} 5$ gives a value of $L \cong 24$ for the 
Table II. UV absorption, fluorescence, molecular weights, degree of polymerization, and isotropic mobility of poly( $n$-alkylphenylsilane)

\begin{tabular}{cccccccc}
\hline Entry & $\begin{array}{c}\lambda_{\max }^{\mathrm{abs}} \\
(\mathrm{nm})\end{array}$ & $\begin{array}{c}\varepsilon^{\mathrm{abs}} \\
\left(\mathrm{mol}^{-1} \mathrm{dm}^{-3} \mathrm{~cm}^{-1}\right)\end{array}$ & $\begin{array}{c}\lambda_{\mathrm{max}}^{\mathrm{fl}} \\
(\mathrm{nm})\end{array}$ & $\begin{array}{c}M_{\mathrm{w}} \\
\left(\times 10^{4}\right)\end{array}$ & $\begin{array}{c}M_{\mathrm{n}} \\
\left(\times 10^{4}\right)\end{array}$ & $\begin{array}{c}\mu_{\mathrm{ID}}^{+} \\
\left(\mathrm{cm}^{2} / \mathrm{V} \cdot \mathrm{s}\right)\end{array}$ \\
\hline PH1-1 & 339 & 7900 & 365 & 49 & 22 & 1700 & $\sim 0.03$ \\
PH1-2 & 339 & 7900 & 365 & 17 & 7.5 & 590 & $\sim 0.02$ \\
PH1-3 & 339 & 7900 & 365 & 4.9 & 3.2 & 250 & $\sim 0.02$ \\
PH1-4 & 339 & 7800 & 365 & 1.7 & 1.1 & 87 & $\sim 0.02$ \\
PH1-5 & 338 & 7800 & 365 & 0.96 & 0.80 & 63 & $\sim 0.02$ \\
PH6-1 & 347 & 12800 & 369 & 98 & 58 & 930 & 0.30 \\
PH6-2 & 347 & 12800 & 369 & 57 & 32 & 510 & 0.27 \\
PH6-3 & 347 & 12000 & 369 & 18 & 8.3 & 130 & 0.26 \\
PH6-4 & 347 & 11700 & 370 & 12 & 6.1 & 98 & 0.15 \\
PH6-5 & 347 & 10500 & 372 & 9.4 & 4.2 & 67 & 0.092 \\
\hline
\end{tabular}

PH1s, with almost no dependence on the molecular weight in the examined range. The PH6s, however, exhibited a significant increase in $\varepsilon^{\text {abs }}$ with chain elongation despite the narrower range of molecular weight. According to eq 5 , the value of $L$ is estimated to be 39 for PH6-1 and 32 for PH6-5. The fractional precipitation procedure employed in this study afforded polysilanes with high molecular weight $\left(>\sim 10^{4}\right)$, low polydispersity $(<2.2)$, and monomodal distributions similar to the Schulz-Zimm distribution for all the precipitates. ${ }^{13}$ Thus, for almost all of the fractionated polysilanes in this section, flexible Kuhn chains with $q$ varying from $1.1 \mathrm{~nm}$ (PH1) to $5.4 \mathrm{~nm}$ (PH6) are considered also acceptable as a first-approximation model of chain configurations except for the lowest molecular weight polymers. As discussed in the previous section, the low excluded volume parameter $\alpha$ in toluene and the low second virial coefficient of polysilanes also supports the small contribution of volume-excluding effects to the conformation of PH6. Thus, on the assumption of $\alpha=1$ for PH6, the substitution of $\left\langle r^{2}\right\rangle$ from eq 3 into eq 4 gives the actual molecular weight:

$$
M=3 R_{\mathrm{g}}^{2} M_{\mathrm{L}} \frac{1}{q}
$$

Atactic polystyrene, which is the calibration standard, exhibits almost the same parameters of $q(0.9 \mathrm{~nm})$ and $M_{\mathrm{L}}\left(104 \mathrm{~g} \mathrm{~mol}^{-1}\right)$ as those of PH1. This strongly suggests that the molecular weight of PH1s measured by GPC reasonably reflects the actual value of $M$. The degree of polymerization $(n)$ calculated using eq 16 is summarized in Table II. The value of $L=32$ for PH6-5, derived from eq 5, is not negligible in comparison with the value of $n=67$. It should be noted that there is an apparent control on segment length in PH64 or PH6-5, which is also supported by the dependence of $L$ on the molecular weight of PH6s.

We have determined the values of $\varepsilon^{\bullet-}$ and $\varepsilon^{\bullet+}$ for both PH1s and PH6s in the previous section by PR-

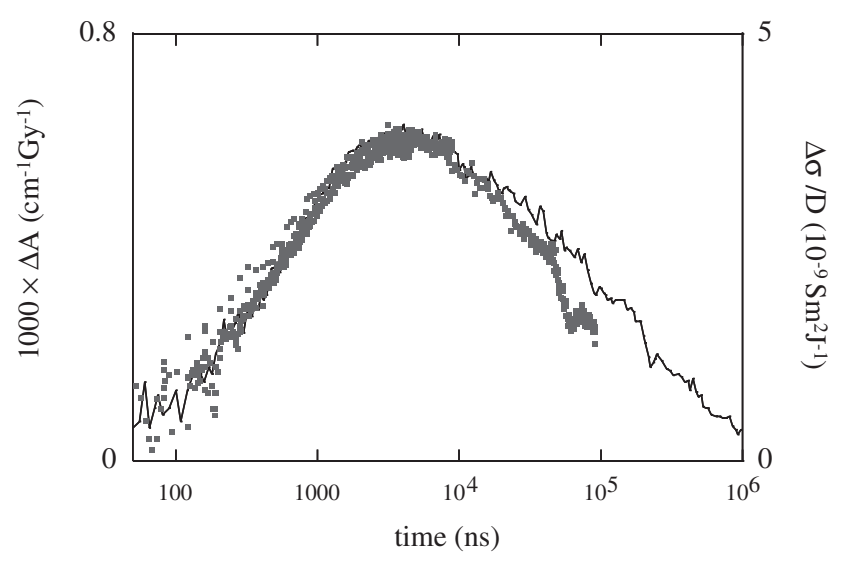

Figure 7. Kinetic trace of transient absorption and microwave conductivity transients of PH6-1 in benzene at $2.0 \mathrm{mmol} \mathrm{dm}^{-3}$ conc. (base mol unit) under $\sim 17 \mathrm{~Gy}$ irradiation. Solid line denotes TRMC transient observed in $\mathrm{O}_{2}$-saturated solution. The TRMC transient was monitored from $10 \mathrm{~ns}$ to $1 \mathrm{~ms}$ using a transient digitizer with a pseudo-logarithmic timebase. Optical transient absorption was recorded at $372 \mathrm{~nm}$.

TAS measurement using an efficient charge transfer reaction to Py (anion radicals) or TMPD (cation radicals), respectively. The yield of PH6-1 ${ }^{\bullet+}$ can be calculated using $\varepsilon^{\bullet+}$ in any time region, and gives the exact number of charge carriers in the benzene solutions. Figure 7 shows the kinetic trace of PH6- $1^{\bullet+}$ over time regions of $10^{-8}$ to $10^{-3} \mathrm{~s}$, together with the observed PR-TRMC signal for the same solution of PH6-1. The maximum yield of $\mathrm{PH}^{-}-1^{\bullet+}$ at $\sim 3 \mu \mathrm{s}$ after pulse irradiation is calculated to be $3.9 \mathrm{nM} \mathrm{Gy}^{-1}$ $\left(\mathrm{G}\left(\mathrm{PH} 6-\mathrm{1}^{\bullet+}\right)=0.044\right.$; G-value of cation radicals, number of radical cations per $100 \mathrm{eV}$ absorbed by the medium) according to the value of $\varepsilon^{\bullet+}$. The formation of PH6- $1^{\bullet+}$ competes with the extinction of $\mathrm{Bz}_{2}{ }^{\bullet+}$ reacting with superoxide anion $\mathrm{O}_{2}{ }^{\bullet-}$, thus the yield of PH6- $1^{\bullet+}$ depends on both the concentration of PH6-1 and the irradiation dose, with the yield decreasing from 3.9 to $1.8 \mathrm{nM} \mathrm{Gy}^{-1}$ with increasing dose from 17 to 158 Gy per pulse, and increasing from 
1.7 to $3.9 \mathrm{nM} \mathrm{Gy}^{-1}$ with increasing concentration of PH6-1 from 0.2 to $2.0 \mathrm{mM}$. The yield of $\mathrm{PH} 1-1^{\bullet+}$ is also determined as $\mathrm{G}\left(\mathrm{PH} 1-1^{\bullet+}\right)=0.048$ by the same procedure. The concentrations of the cation radicals of the other PH1s or PH6s are calculated using the yields observed for PH1-1 or PH6-1, respectively.

In Figure 7, symmetric transients are observed in both TAS and PR-TRMC measurements, and the kinetics of the formation and extinction processes obtained by the two methods are identical under all conditions of PH6 concentration and dose. This indicates that the PR-TRMC signals can be entirely attributed to $\mathrm{PH} 6-1^{\bullet+}$ in the present system. The PR-TRMC method is selective in terms of mobile charges on the polymer chains, allowing the conductivity $(\Delta \sigma)$ of the media to be determined with nanosecond resolution without electrodes. The relationship between the measured conductivity and the mobility is given by ${ }^{26,78}$

$$
\Delta \sigma=1000 F\left[P S^{\bullet \pm}\right] \frac{\mu_{1 D}^{ \pm}}{3}
$$

where $F$ is the Faraday constant, and $\mu_{1 \mathrm{D}}{ }^{+}$is the one dimensional mobility of positive charges moving along polymer backbones. The concentration of PH6$1^{\bullet+}$ can be obtained by TAS measurement, giving $\mu_{1 \mathrm{D}}{ }^{+}=0.30 \mathrm{~cm}^{2} \mathrm{~V}^{-1} \mathrm{~s}^{-1}$, which is consistent with the value derived previously. ${ }^{27}$ The hole drift mobility $\mu$ has been previously reported to be $6 \times 10^{-3}$ to $7 \times$ $10^{-4}$ in electric fields of $3 \times 10^{2}$ to $8 \times 10^{2} \mathrm{~V} \mathrm{~cm}^{-1}$ by DC-TOF. ${ }^{24}$ The present value of the mobility is more than two orders of magnitude higher than that obtained by DC-TOF. Considering the disorder formalism for hopping transport of charge carriers in the disordered molecular solid, the mobility of carriers is expected to be dominated by variations in the displacement of trapping sites and/or in the energy levels of the sites themselves. ${ }^{23,79}$ If the dynamic changes in the backbone conformation of PH6 occur on the time scale of DC-TOF measurements, a reduction of the mobility in the bulk system may occur. However, it should be noted that the isolated one-dimensional $\mathrm{Si}$ skeletons in PH6 have far higher potentials as positive charge conductors than predicted by the DC-TOF technique.

There are few reports that provide an estimate of the electron mobility in polysilanes or other disordered organic solid materials such as $\pi$ - and $\sigma$-conjugated polymers. The microwave conductivity transient for PH6-1 ${ }^{\bullet-}$, generated by the reaction between free electrons in benzene and PH6-1, is shown in Figure 8. The addition of TEA causes a substantial reduction in the conductivity signals of PH6-1 $\mathbf{1}^{\bullet+}$, and the transient display much faster growth and decay. This reflects the faster formation process of $\mathrm{PH}^{-1^{\bullet-}}$ due to the

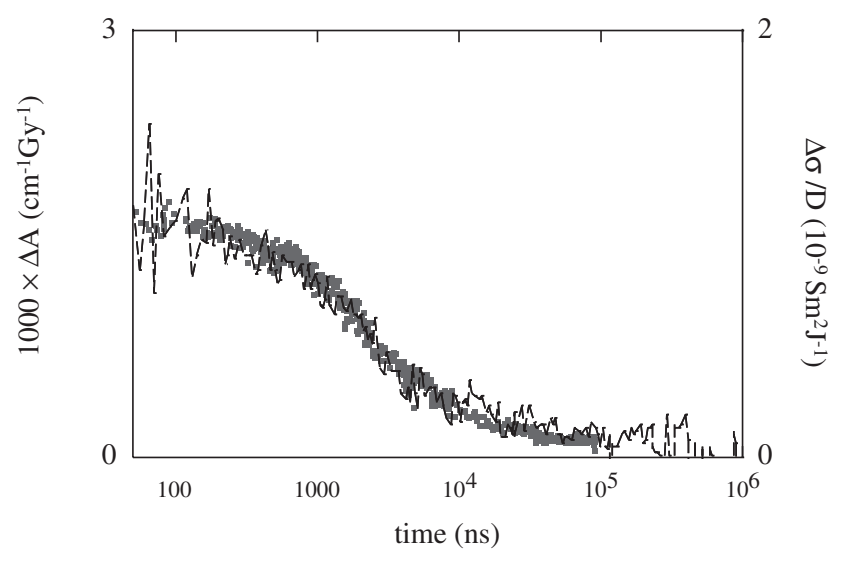

Figure 8. Kinetic trace of transient absorption and microwave conductivity transients of PH6-1 in benzene at $2.0 \mathrm{mmol} \mathrm{dm}^{-3}$ conc. (base mol unit) under $\sim 17 \mathrm{~Gy}$ irradiation. Dashed line denotes TRMC transient observed in deaerated solution with 5.0 mmol dm ${ }^{-3}$ TEA. Optical transient absorption was recorded at $385 \mathrm{~nm}$.

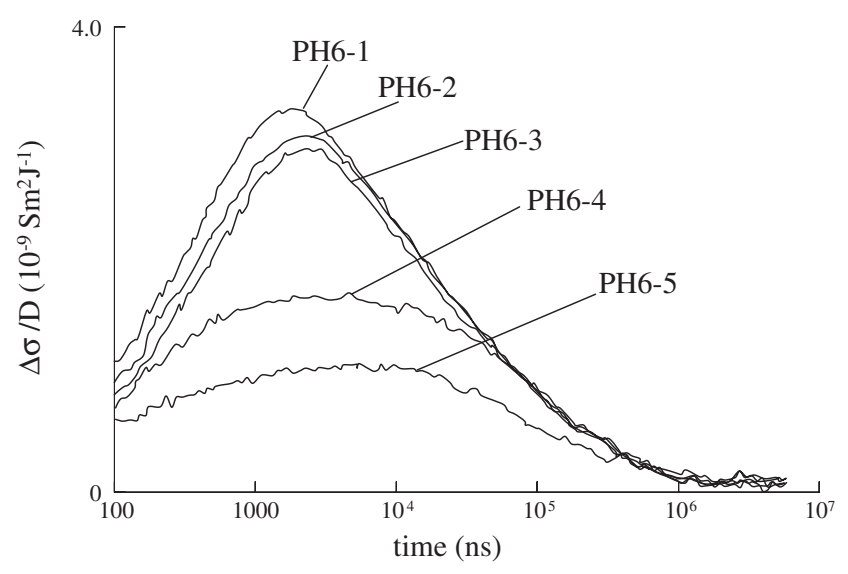

Figure 9. Dose-normalized changes in microwave conductivity during pulse radiolysis of dilute benzene solutions of PH6$1 \sim 5$. In all cases, the concentration was $2.0 \mathrm{mmol} \mathrm{dm}^{-3}$ (base mol unit), and the irradiation dose was $\sim 68 \mathrm{~Gy}$.

higher mobility of electrons in benzene than $\mathrm{Bz}_{2}{ }^{\bullet+}$, and the faster recombination of electrons on the polymer chains with impurities in the solution. On the basis of the anion radical concentration determined by an use of $\varepsilon^{\bullet-}=5.0 \times 10^{4} \mathrm{~mol}^{-1} \mathrm{dm}^{3} \mathrm{~cm}^{-1}$ for PH6- $1^{--}$, the estimated electron mobility $\left(\mu_{1 \mathrm{D}^{-}}\right)$is $6.2 \times 10^{-2} \mathrm{~cm}^{2} \mathrm{~V}^{-1} \mathrm{~s}^{-1}$, indicating that polysilanes provide potential conducting paths for both holes and electrons, although the mobility of electrons is lower than that of holes.

The dependence of the conductivity transients on the chain length of the PH1s and PH6s polymers is shown in Figures 9 and 10. The observed transients depend remarkably on the chain length of PH6s, and reaches saturation for PH6-1 3. The PH1s exhibit less of a dependence on chain length, with absolute values of conductivity lower than those for PH6s. 


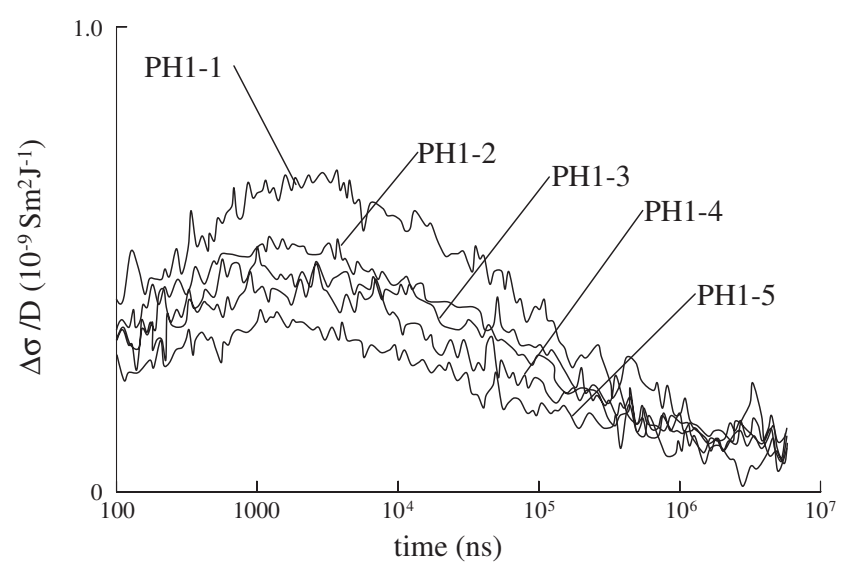

Figure 10. Dose-normalized changes in microwave conductivity during pulse radiolysis of dilute benzene solutions of PH1$1 \sim 5$. In all cases, the concentration was $2.0 \mathrm{mmol} \mathrm{dm}^{-3}$ (base mol unit), and the irradiation dose was $\sim 68 \mathrm{~Gy}$.

The value of $\mathrm{G}\left(\mathrm{PH} 1-1^{\bullet+}\right)$ also gives the concentration of radical cations of $\mathrm{PH} 1-1$ ([PH1-1 $\left.{ }^{\bullet+}\right]$ ), yielding a mobility of $\mu_{1 \mathrm{D}}{ }^{+}=0.0029 \mathrm{~cm}^{2} \mathrm{~V}^{-1} \mathrm{~s}^{-1}$ for PH1. For all the other polysilanes, the values of $\mu_{1 \mathrm{D}}{ }^{+}$relative to PH1-1 or PH1-1 are summarized in Table II. The present results suggest that the highly delocalized $\mathrm{SOMO}^{+}$is achieved in PH6 with long enough Si catenation. The degree of delocalization in PH6 is at least one order of magnitude higher than that in $\mathrm{PH} 1$, as indicated by the saturation of $\mu_{1 \mathrm{D}^{+}}$at $\sim 0.003$ $\mathrm{cm}^{2} \mathrm{~V}^{-1} \mathrm{~s}^{-1}$ for PH1 and $\sim 0.03 \mathrm{~cm}^{2} \mathrm{~V}^{-1} \mathrm{~s}^{-1}$ for PH6 with increasing $n$. This is the case giving considerable increase in $f^{\bullet-}$ or $f^{\bullet+}$ of PH6s in comparison with those of PH1s as suggested by PR-TAS in the previous section. On the other hand, the difference in delocalization is considerably larger than the difference in $L$ ( $\sim 24$ Si units for PH1 and $\sim 39$ units for PH6) derived from eq 5 , and the difference in $q(1.1 \mathrm{~nm}$ for PH1 and $5.4 \mathrm{~nm}$ for PH6). The value of $L$ was estimated from $\varepsilon^{\text {abs }}$ of the steady-state absorption spectra without the contribution of intra-molecular energy transfer processes (exciton migration ${ }^{77}$ ), giving the mean length of the overall conjugated segments. The values of $q$, which reflect the length of physical segmentation in the chains, also provide a measure of the mean length. The conductivity transients measured in the present study were recorded after intra-chain charge transfer processes, which were expected to occur within a few nanoseconds ${ }^{76}$ and as such can be mainly attributed to energetically favorable segments in the polysilane backbones. Transient spectroscopy of the radical ions of a variety of polysilanes has suggested a remarkable contribution from intra-molecular (inter-segment) charge transfer processes. The present results also indicate that this is the case, giving rise particularly to delocalization along the Si chains of PH6 in comparison with the delocalization of the exciton state.

The conductivity transients of PH6s in Figure 10, however, indicate considerable slow rise time for PH6 with short chain length. The difference in the rise time is up to $\sim 10 \mu \mathrm{s}$, which is considerably longer than the time responsible for the intra-molecular charge transfer processes. This might be due to the inter-molecular charge transfer processes, because the small change in the chain length derived from the molecular weight distribution cause relatively higher effects on the single chain mobility in case of the shorter chain polymers. This is also supported by the fact of unsaturated values of the mobility observed especially for PH6-4 5.

Crosslinked $\sigma$-Conjugated Polymer Nanowires by Single Particle Nanofabrication Technique

In this section, the radiation sensitivity of $\sigma$-conjugated polymers is discussed especially upon irradiation to high energy charged particles. The radiation induced reactions in $\sigma$-conjugated polymers have been revealed to depend strongly on the nature of radiation sources: LET which represents concentration of energy deposited by radiations along their paths (trajectories) in the media. ${ }^{45-47}$ Polysilanes were cross-linked by high LET radiations including high energy charged particles, despite of predominant main chain scission reactions observed for low LET radiations or photons. ${ }^{42,43}$ It should be noted that the cross-linking reactions depended strongly on the density of neutral reactive intermediates: silyl radicals, ${ }^{80}$ and the reactions seemed to occur within a nm-scaled cylindrical space along an incident particle trajectory where the intermediates distributed densely and non-homogeneously. ${ }^{45-47}$ This process will potentially give a insoluble "nano-gel" along each corresponding particle, and produce wire-like 1D-nanostructures via isolation of "nano-gel" on a substrate by removing soluble uncross-linked parts. ${ }^{48-56}$

Simple procedures were employed to cause crosslinking reactions: coating of the polymers onto Si substrates at $0.2-1.0 \mu \mathrm{m}$ thick, irradiation to a variety of $\mathrm{MeV}$ order high energy charged particle from several accelerators in vacuum chambers, and washing the film in solvents to remove uncross-linked parts of the film. ${ }^{56}$ After the washing and drying procedures, surface structure of the substrate was observed directly by an atomic force microscope (AFM).

High energy charged particle irradiation of $\mathrm{PH} 1$ films was found to cause gelation of the polymers for all particles, all energies, and all molecular weights of PH1. Figure 11 shows the evolution curves of gel volume for irradiation of PH1 films with $2 \mathrm{MeV} \mathrm{He}^{+}$particles. In the figure, the gel fraction corresponds to the normalized thickness, and the evolution curve was 


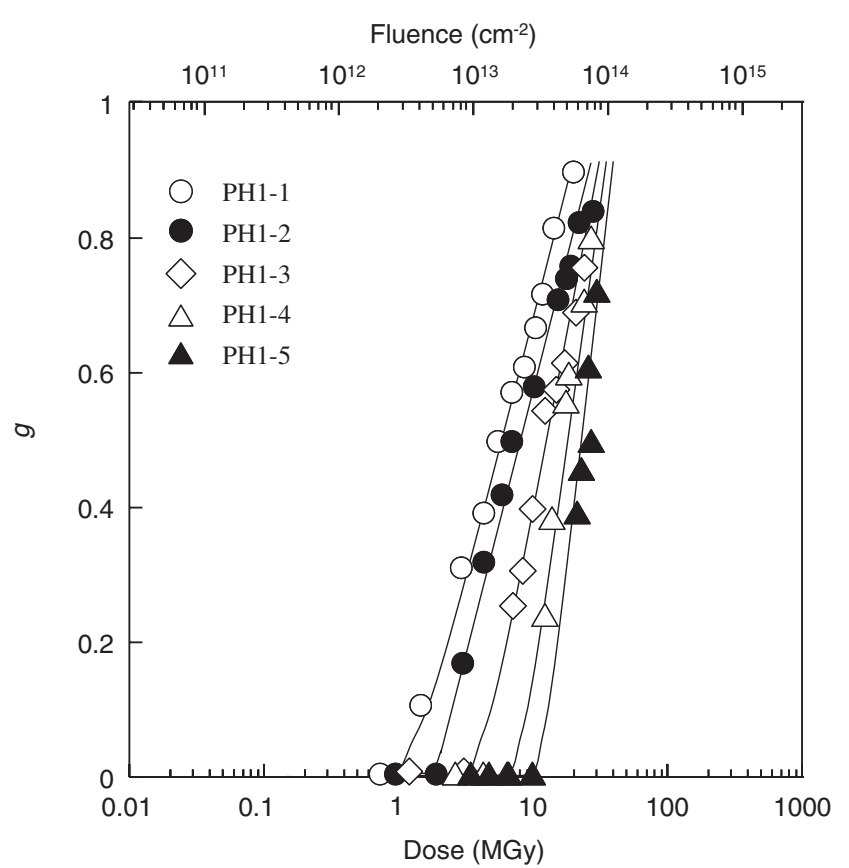

Figure 11. Sensitivity curves (gel evolution curves) for PH1s with various molecular weights under irradiation with a $2 \mathrm{MeV}$ ${ }^{4} \mathrm{He}^{+}$beam. Reprinted with permission from S. Seki, et al., Macromolecules, 38, 10164 (2005) (Ref. 54) (C)2005, American Chemical Society.

calibrated by the absorbed dose $(D)$. According to the statistical theory of cross-linking and scission of polymers induced by radiation, the $G$ values of cross-linking (efficiency of the cross-linking reaction, $G(x)$ ) and main-chain scission $(G(s))$ are expressed by the Charlesby-Pinner relationship as follows. ${ }^{81,82}$

$$
\begin{aligned}
& s+s^{1 / 2}=p / q+\frac{m}{q} M_{\mathrm{n}} D \\
& s=1-g \\
& G(x)=4.8 \times 10^{3} q \\
& G(s)=9.6 \times 10^{3} p
\end{aligned}
$$

where $p$ is the probability of scission, $q$ is the probability of cross-linking, $s$ is the sol fraction, $g$ is the gel fraction, $m$ is the molecular weight of a unit monomer, and $M_{\mathrm{n}}$ is the number average molecular weight before irradiation. The cross-linking $G$ values calculated using these equations for irradiation of $\mathrm{PH} 1$ with $2 \mathrm{MeV} \mathrm{He}^{+}, \mathrm{H}^{+}, \mathrm{C}^{+}$, and $\mathrm{N}^{+}$particles are compared in Table III. The values of $G(x)$ for high molecular weight PH1 are much lower than those for low molecular weight PH1. Besides chain length, there are no differences in the chemical structures of the polymers, indicating that the efficiency of cross-linking should be identical for all series of polymers to a first approximation. The effects of the molecular weight distribution on the radiation-induced gelation of a real polymer system were considered by Saito ${ }^{83}$ and Inokuti, ${ }^{84}$ who traced the changes in distribution due to simultaneous reactions of main-chain scission and cross-linking analytically. However, in the present case, the molecular weight distributions of the target polymers are reasonably well controlled to be less than 1.2, and the initial distributions are predicted not to play a major role in gelation. The simultaneous change in the molecular weight distribution due to radiation-induced reactions also results in a non-linearity of eqs 1 and 2 . Therefore, the following equations are proposed to extend the validity of the relationship by introducing a deductive distribution function of molecular weight on the basis of an arbitrary distribution: ${ }^{85}$

$$
\begin{aligned}
& s+s^{1 / 2}=p / q+\frac{(2-p / q)\left(D_{\mathrm{V}}-D_{\mathrm{g}}\right)}{\left(D_{\mathrm{V}}-D\right)} \\
& D_{\mathrm{v}}=4\left(\frac{1}{u u_{n}}-\frac{1}{u_{w}}\right) / 3 q
\end{aligned}
$$

where $D_{\mathrm{g}}$ is the gelation dose, and $u$ is the degree of polymerization. Eq 22 provides a better fit to the observed values of $s$ at high doses than eq 18, as shown in Figure 12. However, the $G(x)$ derived from this fit are almost identical to those in Table III, depending on the molecular weight, because the values are estimated in the low-dose region where eq 18 is sufficiently linearity.

The effects of the polymer structure ${ }^{15}$ and the cross-

Table III. Values of $G(x)$ determined for various high energy particles and polymer chain lengths ${ }^{\mathrm{a}}$

\begin{tabular}{cccccc}
\hline \multirow{2}{*}{ Entry } & $\begin{array}{c}2 \mathrm{MeV} \mathrm{H} \\
15 \mathrm{eV} / \mathrm{nm}\end{array}$ & $\begin{array}{c}2 \mathrm{MeV} \mathrm{He} \\
220 \mathrm{eV} / \mathrm{nm}\end{array}$ & $\begin{array}{c}0.5 \mathrm{MeV} \mathrm{C} \\
410 \mathrm{eV} / \mathrm{nm}\end{array}$ & $\begin{array}{c}2 \mathrm{MeV} \mathrm{C} \\
720 \mathrm{eV} / \mathrm{nm}\end{array}$ & $\begin{array}{c}2 \mathrm{MeV} \mathrm{N} \\
790 \mathrm{eV} / \mathrm{nm}\end{array}$ \\
\hline \multirow{2}{*}{ PH1-1 } & 0.0018 & 0.0049 & 0.021 & 0.072 & 0.082 \\
& $(0.0021)^{\mathrm{b}}$ & $(0.0052)^{\mathrm{b}}$ & $(0.022)^{\mathrm{b}}$ & $(0.0079)^{\mathrm{b}}$ & $(0.0095)^{\mathrm{b}}$ \\
PH1-2 & 0.0021 & 0.0095 & 0.052 & 0.081 & 0.15 \\
PH1-3 & 0.0030 & 0.019 & 0.07 & 0.18 & 0.21 \\
PH1-4 & 0.0075 & 0.021 & 0.075 & 0.20 & 0.26 \\
PH1-5 & 0.019 & 0.061 & 0.18 & 0.27 & 0.34 \\
& $(0.021)^{\mathrm{b}}$ & $(0.089)^{\mathrm{b}}$ & $(0.19)^{\mathrm{b}}$ & $(0.33)^{\mathrm{b}}$ & $(0.42)^{\mathrm{b}}$ \\
\hline
\end{tabular}

${ }^{\mathrm{a}}$ All the data are quoted from refs. 43,49 , and $54,{ }^{\mathrm{b}}$ Values in the parenthesis were estimated by eqs 22 and 23. 


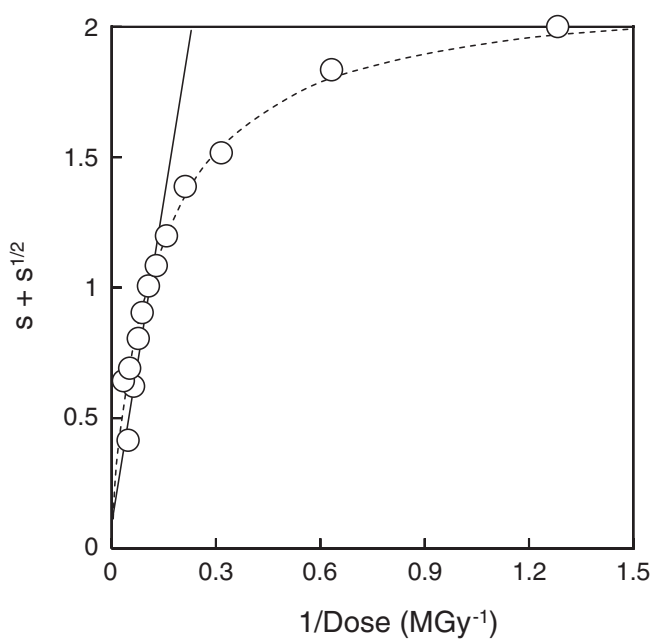

Figure 12. Charlesby-Pinner plot of $s+s^{1 / 2} v s .1 / D$ for $2 \mathrm{MeV}{ }^{4} \mathrm{He}^{+}$irradiation of PH1-1. Solid line denotes the fit by eq 18 in the high-dose region for the estimation of $G(x)$ in Table III. Dashed line is given by eq 22 for the entire dose region. Reprinted with permission from S. Seki, et al., Macromolecules, 38, 10164 (2005) (Ref. 54) (C)2005, American Chemical Society.

linking precursor species ${ }^{86}$ have been considered in previous studies, where it was revealed that there was less of a dependence of $G(x)$ on the molecular weight in the case of $\gamma$-rays or electron beam irradiation. The cross-linking points in polymer materials are distributed non-homogeneously on an ion track along an ion trajectory. A schematic of this type of nonhomogeneous distribution is shown in Figure 13. Intra-molecular cross-linking, which constitutes a greater contribution to $G(x)$ in the inner region of ion tracks associated with higher densities of deposited energy, is not taken into account by the statistical treatment in eqs $18-23$, and it is this case that gives rise to an underestimate of the number of crosslinks. As the polymer film used in the present study is sufficiently thin to allow the change in kinetic energy of incident particle to be neglected, a model of cylindrical energy deposition is sufficient, without needing to refer to the dependence of the radial energy distribution on the direction of the ion trajectory. The total yield of gels generated by charged particle irradiation can thus be treated using a simplified expression, ${ }^{42,44,47,54}$ as follows.

$$
g=1-\exp \left[-n \pi r_{\mathrm{cc}}{ }^{2}\right]
$$

Here, $r_{\mathrm{cc}}$ is the radius of the cross-section of the cylindrical region (chemical core), and $n$ represents the fluence of incident ions. The effect of the diffusion of reactive intermediates, determined using a low-energy charged particle, has been formulated as the term $\delta r:{ }^{47}$

$$
r_{\mathrm{cc}}=r^{\prime}+\delta r^{\prime}
$$

The value of $\delta r^{\prime}$ in PH1 was determined to be $0.5-0.7$ $\mathrm{nm} .{ }^{47}$ Based on traces of the gel fraction by eq 24 , the estimated values of $r_{\mathrm{cc}}$ are summarized for a variety of high energy charged particles in Table IV. The value of $r_{\mathrm{cc}}$ increases substantially with molecular weight in all cases except for irradiation with $2 \mathrm{MeV} \mathrm{H}^{+}$, suggesting that the cylindrical scheme may not be applicable for the $2 \mathrm{MeV} \mathrm{H}^{+}$because the deposited energy density is too low to promote the cylindrical distribution of crosslinks in an ion track.

AFM images of the cylindrical gel area are shown in Figure 14 for comparison with traces of the gel

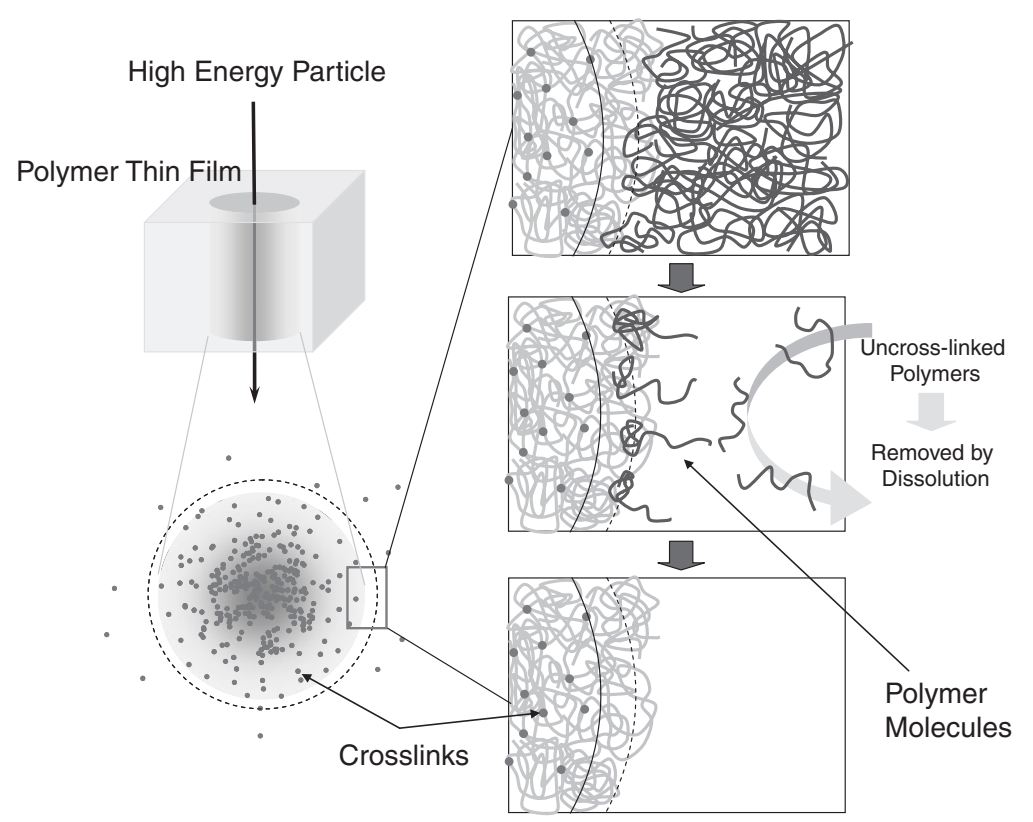

Figure 13. Schematic of the non-homogeneous distribution of crosslinks in an ion track. Dissolution of non-crosslinked molecules results in the formation of isolated nanowires. 
Table IV. Values of $r_{\mathrm{cc}}$ for various high energy particles and polymer chain lengths

\begin{tabular}{|c|c|c|c|c|c|c|c|}
\hline Ions & $\begin{array}{l}\text { Energy } \\
(\mathrm{MeV})\end{array}$ & $\begin{array}{c}\text { LET } \\
(\mathrm{eV} / \mathrm{nm})\end{array}$ & $\begin{array}{c}r_{\mathrm{cc}} \text { for PH1-1 } \\
(\mathrm{nm})\end{array}$ & $\begin{array}{c}r_{\mathrm{cc}} \text { for PH1-2 } \\
(\mathrm{nm})\end{array}$ & $\begin{array}{c}r_{\mathrm{cc}} \text { for PH1-3 } \\
(\mathrm{nm})\end{array}$ & $\begin{array}{c}r_{\mathrm{cc}} \text { for PH1-4 } \\
(\mathrm{nm})\end{array}$ & $\begin{array}{c}r_{\mathrm{cc}} \text { for PH1-5 } \\
(\mathrm{nm})\end{array}$ \\
\hline${ }^{1} \mathrm{H}^{\mathrm{b}}$ & 2.0 & 15 & 0.15 & 0.15 & 0.14 & 0.14 & 0.15 \\
\hline${ }^{4} \mathrm{He}^{\mathrm{b}}$ & 2.0 & 220 & 1.2 & 0.95 & 0.76 & 0.60 & 0.52 \\
\hline${ }^{12} \mathrm{C}^{\mathrm{b}}$ & 0.50 & 410 & 2.2 & 2.1 & 1.6 & 1.1 & 0.94 \\
\hline${ }^{12} \mathrm{C}^{\mathrm{b}}$ & 2.0 & 720 & 5.0 & 4.3 & 4.0 & 3.4 & 2.7 \\
\hline${ }^{14} \mathrm{~N}^{\mathrm{b}}$ & 2.0 & 790 & 5.1 & 4.8 & 4.2 & 3.8 & 3.0 \\
\hline${ }^{14} \mathrm{~N}^{\mathrm{c}}$ & 2.0 & 790 & 4.8 & 4.8 & 4.3 & 3.6 & 2.8 \\
\hline${ }^{56} \mathrm{Fe}^{\mathrm{c}}$ & 5.1 & 1550 & & & & 5.5 & \\
\hline${ }^{28} \mathrm{Si}^{\mathrm{c}}$ & 5.1 & 1620 & & & & 5.9 & \\
\hline${ }^{28} \mathrm{Si}^{\mathrm{c}}$ & 10.2 & 2150 & & & & 6.1 & \\
\hline${ }^{40} \mathrm{Ar}^{\mathrm{c}}$ & 175 & 2200 & 8.2 & 7.3 & & 6.1 & 4.0 \\
\hline${ }^{56} \mathrm{Fe}^{\mathrm{c}}$ & 8.5 & 2250 & & & & 5.8 & \\
\hline${ }^{56} \mathrm{Fe}^{\mathrm{c}}$ & 10.2 & 2600 & & & & 7.7 & \\
\hline${ }^{84} \mathrm{Kr}^{\mathrm{b}}$ & 520 & 4100 & 10.7 & 9.6 & 8.6 & 7.9 & 6.4 \\
\hline${ }^{84} \mathrm{Kr}^{\mathrm{c}}$ & 520 & 4100 & 10.2 & 9.2 & 8.3 & & 6.1 \\
\hline${ }^{129} \mathrm{Xe}^{\mathrm{c}}$ & 450 & 8500 & 12.1 & 10.5 & 9.3 & & 6.9 \\
\hline${ }^{192} \mathrm{Au}^{\mathrm{c}}$ & 500 & 11600 & 19.4 & & 16.2 & 12.5 & 10.7 \\
\hline
\end{tabular}

${ }^{\mathrm{a}}$ All the data are quoted from refs. 49 , and $54 .{ }^{\mathrm{b}}$ Values estimated from gel traces by eq $24 .{ }^{\mathrm{c}}$ Values estimated by direct AFM observation.
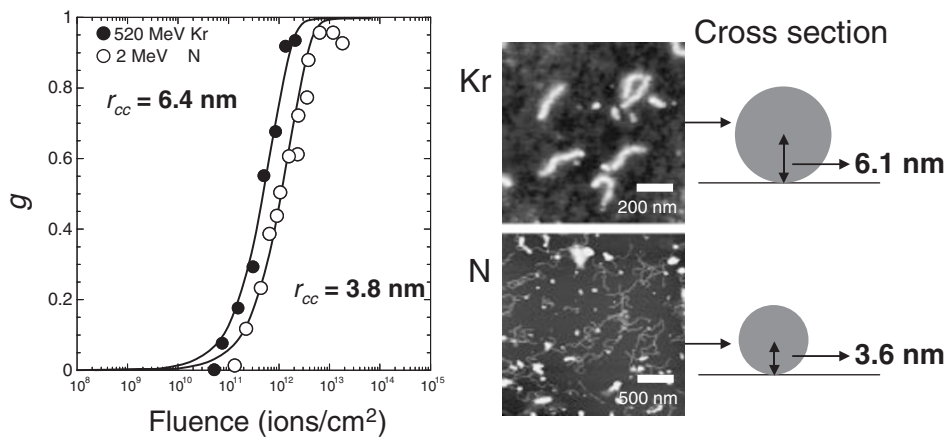

Figure 14. Gel evolution curves recorded for $520 \mathrm{MeV}^{84} \mathrm{Kr}$ irradiation of PH1-5 and $2 \mathrm{MeV}{ }^{14} \mathrm{~N}$ irradiation of PH1-4. Solid lines denote the fit for the respective gel fraction based on eq 24. The estimated values of $r_{\mathrm{cc}}$ are 6.4 and $3.8 \mathrm{~nm}$ for the $\mathrm{Kr}$ and $\mathrm{N}$ particles. AFM micrographs were observed for the same set of polymers and particles. The fluence of $\mathrm{Kr}$ and $\mathrm{N}$ ions was set at $1.4 \times 10^{10}$ and $6.4 \times 10^{9} \mathrm{~cm}^{-2}$, respectively. Reprinted with permission from S. Seki, et al., Macromolecules, 38, 10164 (2005) (Ref. 54) (C) 2005, American Chemical Society.
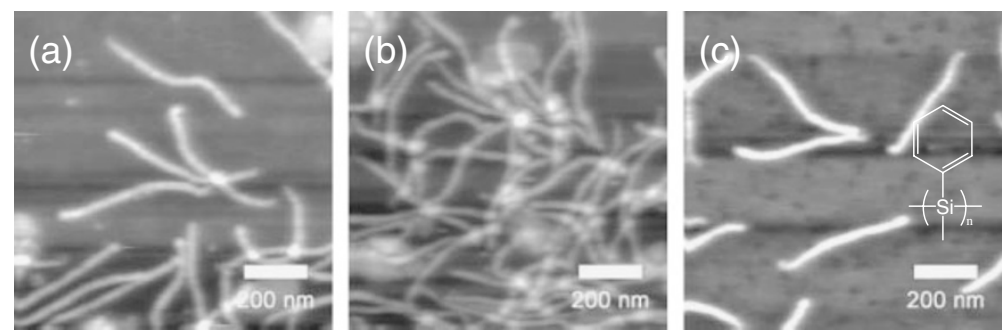

Figure 15. AFM micrographs of nanowires based on PH1s showing the variation in size with molecular weight and number density on the substrate. The nanowires were formed by $500 \mathrm{MeV}{ }^{192} \mathrm{Au}$ beam irradiation to (a,b) PH1-3 (c) PH1-1 thin films at (a) $3.0 \times 10^{9}$, (b) $5.0 \times 10^{9}$, and (c) $1.0 \times 10^{9}$ ions $/ \mathrm{cm}^{2}$, respectively. The thickness of the target films were (a,b) $350 \mathrm{~nm}$ and (c) $250 \mathrm{~nm}$.

fraction. Eq 24 provides a good fit for the trace of the gel fraction, and the estimated values of $r_{\mathrm{cc}}$ for both particles correspond with the values observed from the AFM micrographs. Figure 15 shows a series of AFM micrographs observed for the irradiation of
PH1-1 and PH1-3 thin films with varying number of incident particles. These images clearly reveal 1D rod-like structures (nanowires) on the substrate, which is ascribed to the cylindrical formation of nano-gel along ion trajectories. It should be noted that the den- 
sity of the nanowires on the substrate increased clearly with an increase in the number of the incident particles, and the observed number density of the nanowires coincided with the number density of the incident particle. This is also suggestive that "one nanowire" is produced corresponding incident particle along its trajectory, which is a clear evidence of the model described above. As shown in Figure 15, the length of the nanowires is uniform in each image, and is consistent precisely with the initial thickness of the film. This is due to the geometrical limitation of the distribution of cross-liking reaction: the gelation occurs from the top-surface to bottom of the polymer film. Thus the length of the nanowires can be perfectly controlled by the present technique. Based on the measurement of cross-sectional trace of the nanowires by AFM, the radial distribution of crosslinks in the nanowires is discussed in terms of $r_{\mathrm{cc}}$ defined as the radius of the cross-section. It is clear that the value of $r_{\mathrm{cc}}$ depends on the molecular weight of the target polymer as shown in Figure 15, and the $r_{\mathrm{cc}}$ also changes with the LET of incident particle as summarized in Table IV.

The authors previously reported that cross-linking reactions are mainly promoted by side-chain dissociated silyl radicals, and that the predominant reaction is determined by the radical concentration in the ion tracks. ${ }^{15,42,43,86}$ Thus, the distribution of crosslinks in an ion track is expected to reflect the radial dose (deposited energy density) distribution, where $\rho_{\text {cr }}$ is the critical energy density for the predominance of cross-linking in PH1. The radial dose distribution in an ion track is thus given by ${ }^{45,46}$

$$
\begin{gathered}
\rho_{\mathrm{c}}=\frac{L E T}{2}\left[\pi r_{\mathrm{c}}^{2}\right]^{-1}+\frac{L E T}{2}\left[2 \pi r_{\mathrm{c}}{ }^{2} \ln \left(\frac{e^{1 / 2} r_{\mathrm{p}}}{r_{\mathrm{c}}}\right)\right]^{-1} \\
r \leq r_{\mathrm{c}} \\
\rho_{\mathrm{p}}(r)=\frac{L E T}{2}\left[2 \pi r^{2} \ln \left(\frac{e^{1 / 2} r_{\mathrm{p}}}{r_{\mathrm{c}}}\right)\right]^{-1} \\
r_{\mathrm{c}}<r \leq r_{\mathrm{p}}
\end{gathered}
$$

where $\rho_{\mathrm{c}}$ is the deposited energy density in the core area, and $r_{\mathrm{c}}$ and $r_{\mathrm{p}}$ are the radii of the core and penumbra area. For gel formation in a polymer system, it is necessary to introduce one crosslink per polymer molecule. Assuming a sole contribution from the cross-linking reactions in the chemical core, $\rho_{\text {cr }}$ is given by

$$
\rho_{\mathrm{cr}}=\frac{100 \rho A}{G(x) m N}
$$

where $A$ is Avogadro's number, and $N$ is the degree of polymerization. The value of $m N / \rho A$ reflects the volume of a polymer molecule. Substitution of $\rho_{\mathrm{p}}(r)$ in eq 27 with $\rho_{\text {cr }}$ gives the following requirement for $r^{\prime} .47,48$

$$
r^{\prime 2}=\frac{L E T G(x) m N}{400 \pi \rho A}\left[\ln \left(\frac{e^{1 / 2} r_{\mathrm{p}}}{r_{\mathrm{c}}}\right)\right]^{-1}
$$

Using the reported value of $G(x)=0.12$, derived from radiation-induced changes in molecular weight, ${ }^{43}$ the values of $r_{\mathrm{cc}}$ calculated by the non-empirical formulation of eq 29 are compared with the experimental values showing a good consistency with the experimental values for polymers with sufficient chain length (PH1-1 and PH1-2). However, a considerable discrepancy occurs between the calculated and experimental results for polymers with shorter chains. The global configuration of the polymer molecules depends heavily on the length of the polymer chains, leading to transformation from random coil (long chain) to rod-like (short chain) conformations. The gyration radius of a polymer molecule, which determines the size of a molecule spreading in the media, is correlated with this transformation. The correlation between $R_{\mathrm{g}}$ and $N$ is discussed in the previous sections, giving eq 2. Based on the persistence length of PH1 (1.1 nm, see previous section), the scaling law for a helical worm-like chain model ${ }^{87}$ results in an index $\alpha$ of $0.410,0.419,0.451,0.485$, and 0.492 for PH1-1 5, respectively. Thus, the effective volume of a polymer chain can be simply calculated as $4 / 3 \pi R_{\mathrm{g}}{ }^{3}$, and the substitution of $m N / \rho A$ in eq 28 with the effective volume leads the expression ${ }^{54,56}$

$$
r^{\prime 2}=\frac{L E T G(x) N^{3 \alpha}}{400 \pi \beta}\left[\ln \left(\frac{e^{1 / 2} r_{\mathrm{p}}}{r_{\mathrm{c}}}\right)\right]^{-1}
$$

where $\beta$ is the effective density parameter of the monomer unit $\left(\mathrm{kg} \mathrm{m}^{-3}\right)$. Based on eq 30, the calculated value of $r_{\mathrm{cc}}$ is plotted again the experimental values in Figure 16. All polymers, with a variety of molecular weights, follow a single trend, and the calculated values display good correspondence in the range $r_{\mathrm{cc}}>7 \mathrm{~nm}$. The underestimate of $r_{\mathrm{cc}}$ by eq 30 for $r_{\mathrm{cc}}<7 \mathrm{~nm}$ suggests that the initial deposition of energy and the radial dose distribution estimated by eqs 26 and 27 do not account for the radial distribution of chemical intermediates and thus cannot model the concentration of cross-linking in the core of the ion track. The value of $G(x)$ increases dramatically with an increase in the density of reactive intermediates. Based on the assumption that $G(x)$ is a function of the density of deposited energy, the present results indicate that the yield of the chemical reaction is dependent on the energy density. Cross-linking reactions in ion tracks therefore have potential for not only single-particle fabrication with sub-nanometer-scale spatial resolution for any kind of cross-linking polymers, 


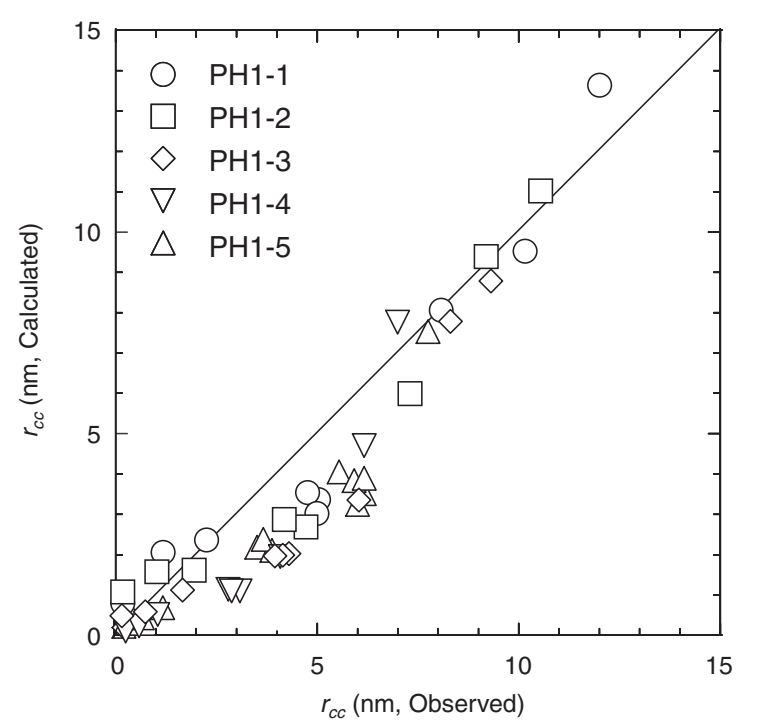

Figure 16. Correlation between $r_{\mathrm{cc}}$ values estimated experimentally and those calculated using eq 30 . Reprinted with permission from S. Seki, et al., Macromolecules, 38, 10164 (2005) (Ref. 54) (C)2005, American Chemical Society.

but also the study of nano-scale distributions of radial dose and chemical yield in an ion track.

\section{CONCLUSION}

Spectroscopic measurement results of ion radicals of $\sigma$-conjugated polymers were quantitatively discussed in terms of oscillator strength, hence the delocalization degree of excess charges along their $\sigma$-conjugated skeletons. The principal role of sidechain pendant groups was suggested for delocalization of positive charge, despite of the insulating nature of the side chains for electrons delocalized over $\mathrm{Si}$ catenations. The quantitative analysis of the transient absorption spectra also gave precise number (concentration) of charge carriers generated in the media. This realizes fully experimental determination of intra-chain charge carrier mobility by the techniques combined with the electrodeless PR-TRMC measurement. The intrinsic mobility of charge carriers along stiff $\sigma$-conjugated backbones revealed to be up to $\sim 0.3 \mathrm{~cm}^{2} \mathrm{~V}^{-1} \mathrm{~s}^{-1}$ for positive charges and $\sim 0.06$ $\mathrm{cm}^{2} \mathrm{~V}^{-1} \mathrm{~s}^{-1}$ for negative charges, suggesting the presence of highly conductive paths for not only holes but also electrons in the stiff or rod-like polymer molecules. Cross-linking reaction of $\sigma$-conjugated polymers was also achieved by an use of $\mathrm{MeV}$-order high energy charged particles. Cross-linking reactions occurred within a nano-sized cylindrical area where the reactive intermediates distributed densely and non-homogeneously by the energy deposition of an incident particle. The wire-like nanostructures were successfully isolated on substrates by the simple pro- cedure, and observed clearly by AFM. This is suggestive that the nano-sized cylindrical field of crosslinking reactions induced by an charged particle is applicable to produce nanowires based on a variety of polymeric materials.

Acknowledgment. The authors thank Dr. S. Tsukuda, Dr. A. Saeki, Ms. T. Kawaguchi, Ms. Y. Koizumi, and Dr. A. Acharya of the Institute of Scientific and Industrial Research (ISIR), Osaka University, and Dr. M. Sugimoto of the Japan Atomic Energy Research Agency for experimental support. We also acknowledge Prof. J. M. Warman, Prof. L. D. A. Siebbeles, Dr. F. Grozema, Dr. L. P. Candeias, and Dr. M. P. de Haas of Delft University of Technology for useful discussions on TRMC measurements. This work was supported in part by a Grant-in-Aid for Scientific Research from the Japan Society for the Promotion of Science (JSPS).

\section{REFERENCES}

1. M. Rice, J. Phys. Lett., 71A, 152 (1979).

2. R. West, J. Organomet. Chem., 300, 327 (1986).

3. P. Trefonas, R. West, and R. D. Miller, J. Am. Chem. Soc., 107, 2737 (1985).

4. F. Kajzar, J. Messier, and C. Rosilio, J. Appl. Phys., 60, 3040 (1986).

5. R. G. Kepler, J. M. Zeigler, L. A. Harrah, and S. R. Kurtz, Phys. Rev. B: Condens. Matter Mater. Phys., 35, 2818 (1987).

6. H. Suzuki, H. Meyer, S. Hoshino, and D. Haarer, J. Lumin., 66-67, 423 (1996).

7. M. Fujino, Chem. Phys. Lett., 136, 451 (1987).

8. M. A. Abkowitz, F. E. Knier, H. J. Yuh, R. J. Weagley, and M. Stolka, Solid State Commun., 62, 547 (1987).

9. M. Fujiki, J. Am. Chem. Soc., 118, 7424 (1996).

10. M. Fujiki, J. Am. Chem. Soc., 116, 6017 (1994).

11. J. R. Koe, M. Fujiki, H. Nakashima, and M. Motonaga, Chem Commun., 389 (2000).

12. H. Ban, K. Sukegawa, and S. Tagawa, Macromolecules, 20, 1775 (1987).

13. S. Seki, Y. Koizumi, T. Kawaguchi, H. Habara, and S. Tagawa, J. Am. Chem. Soc., 126, 3521 (2004).

14. J. Kumagai, H. Yoshida, and T. Ichikawa, J. Phys. Chem., 99, 7965 (1995).

15. S. Seki, K. R. Cromack, A. D. Trifunac, Y. Yoshida, S. Tagawa, K. Asai, and K. Ishigure, J. Phys. Chem. B, 102, 8367 (1998).

16. K. Seki, T. Mori, H. Inokuchi, and K. Murano, Bull. Chem. Soc. Jpn., 61, 351 (1988).

17. H. Ishii, A. Yuyama, S. Norioka, K. Seki, S. Hasegawa, M. Fujino, H. Isaka, M. Fujiki, and N. Matsumoto, Synth. Met., 69, 595 (1995).

18. S. Seki, Y. Matsui, Y. Yoshida, S. Tagawa, J. R. Koe, and M. Fujiki, J. Phys. Chem. B, 106, 6849 (2002).

19. S. Seki, Y. Yoshida, S. Tagawa, and K. Asai, Macromolecules, 32, 1080 (1999). 
20. S. Seki, Y. Yoshida, and S. Tagawa, Radiat. Phys. Chem., 60, 411 (2001).

21. S. Seki, Y. Kunimi, K. Nishida, Y. Yoshida, and S. Tagawa, J. Phys. Chem. B, 105, 900 (2001).

22. T. Kawaguchi, S. Seki, K. Okamoto, A. Saeki, Y. Yoshida, and S. Tagawa, Chem. Phys. Lett., 374, 353 (2003).

23. S. Seki, Y. Yoshida, S. Tagawa, K. Asai, K. Ishigure, K. Furukawa, M. Fujiki, and N. Matsumoto, Philos. Mag. B, 79, 1631 (1999).

24. Y. Kunimi, S. Seki, and S. Tagawa, Solid State Commun., 114, 469 (2000).

25. G. P. van der Laan, M. P. de Haas, A. Hummel, H. Frey, S. Sheiko, and M. Möller, Macromolecules, 27, 1897 (1994).

26. R. J. O. M. Hoofman, M. P. de Haas, L. D. A. Siebbeles, and J. M. Warman, Nature, 392, 54 (1998).

27. F. C. Grozema, L. D. A. Siebbeles, J. M. Warman, S. Seki, S. Tagawa, and U. Scherf, Adv. Mater., 14, 228 (2002).

28. J. M. Warman, G. H. Gelinck, and M. P. de Haas, J. Phys.: Condens. Matter, 14, 9935 (2002).

29. A. Acharya, S. Seki, A. Saeki, Y. Koizumi, and S. Tagawa, Chem. Phys. Lett., 404, 356 (2005).

30. A. Saeki, S. Seki, T. Sunagawa, K. Ushida, and S. Tagawa, Philos. Mag., 86, 1261 (2006).

31. A. Saeki, S. Seki, Y. Koizumi, T. Sunagawa, K. Ushida, and S. Tagawa, J. Phys. Chem. B, 109, 10015 (2005).

32. C. A. van Walree, T. J. Cleij, L. W. Jenneskens, E. J. Vlietstra, G. P. van der Laan, M. P. de Haas, and E. T. Lutz, Macromolecules, 29, 7362 (1996).

33. H. Frey, M. Moller, M. P. deHaas, J. P. Zenden, P. G. Schouten, G. P. van der Laan, and J. M. Warman, Macromolecules, 26, 89 (1993).

34. G. P. van der Laan, M. P. de Haas, J. M. Warman, H. Frey, and M. Moller, Mol. Cryst. Liq. Cryst., 236, 165 (1993).

35. S. Seki, A. Acharya, Y. Koizumi, A. Saeki, S. Tagawa, and K. Mochida, Chem. Lett., 34, 1690 (2005).

36. Y. Yamamoto, T. Fukushima, W. Jin, A. Kosaka, T. Hara, T. Nakamura, A. Saeki, S. Seki, S. Tagawa, and T. Aida, Adv. Mater., 18, 1297 (2006).

37. R. Yamagami, K. Kobayashi, A. Saeki, S. Seki, and S. Tagawa, J. Am. Chem. Soc., 128, 2213 (2006).

38. A. Saeki, S. Seki, and S. Tagawa, J. Appl. Phys., 100, 0237031 (2006).

39. Y. Yamamoto, T. Fukushima, Y. Suna, N. Ishii, A. Saeki, S. Seki, M. Taniguchi, S. Tagawa, T. Kawai, and T. Aida, Science, 314, 1761 (2006).

40. A. Acharya, S. Seki, Y. Koizumi, A. Saeki, and S. Tagawa, J. Phys. Chem. B, 109, 20174 (2005).

41. A. Acharya, S. Seki, A. Saeki, and S. Tagawa, Synth. Met., 156, 293 (2006).

42. S. Seki, K. Maeda, Y. Kunimi, S. Tagawa, Y. Yoshida, H. Kudoh, M. Sugimoto, Y. Morita, T. Seguchi, T. Iwai, H. Shibata, K. Asai, and K. Ishigure, J. Phys. Chem. B, 103, 3043 (1999).

43. S. Seki, H. Shibata, H. Ban, K. Ishigure, and S. Tagawa, Radiat. Phys. Chem., 48, 539 (1996).

44. S. Seki, K. Kanzaki, Y. Yoshida, H. Shibata, K. Asai, S. Tagawa, and K. Ishigure, Jpn. J. Appl. Phys., Part 1, 36, 5361 (1997).

45. J. L. Magee and A. Chatterjee, J. Phys. Chem., 84, 3529
(1980).

46. A. Chatterjee and J. L. Magee, J. Phys. Chem., 84, 3537 (1980).

47. S. Seki, S. Tsukuda, K. Maeda, Y. Matsui, A. Saeki, and S. Tagawa, Phys. Rev. B: Condens. Matter Mater. Phys., 70, 144203 (2004).

48. S. Tsukuda, S. Seki, M. Sugimoto, and S. Tagawa, Appl. Phys. Lett., 87, 233119 (2005).

49. S. Seki, K. Maeda, S. Tagawa, H. Kudoh, M. Sugimoto, Y. Morita, and H. Shibata, Adv. Mater., 13, 1663 (2001).

50. S. Seki, S. Tsukuda, Y. Yoshida, T. Kozawa, S. Tagawa, M. Sugimoto, and S. Tanaka, Jpn. J. Appl. Phys., Part 1, 43, 4159 (2003).

51. S. Tsukuda, S. Seki, A. Saeki, T. Kozawa, S. Tagawa, M. Sugimoto, A. Idesaki, and S. Tanaka, Jpn. J. Appl. Phys., Part 1, 43, 3810 (2004).

52. S. Tsukuda, S. Seki, S. Tagawa, M. Sugimoto, A. Idesaki, S. Tanaka, and A. Ohshima, J. Phys. Chem. B, 108, 3407 (2004).

53. S. Tsukuda, S. Seki, M. Sugimoto, and S. Tagawa, Jpn. J. Appl. Phys., Part 1, 44, 5839 (2005).

54. S. Seki, S. Tsukuda, K. Maeda, S. Tagawa, H. Shibata, M. Sugimoto, K. Jimbo, I. Hashitomi, and A. Koyama, Macromolecules, 38, 10164 (2005).

55. S. Tsukuda, S. Seki, M. Sugimoto, and S. Tagawa, J. Phys. Chem. B, 110, 19319 (2006).

56. S. Seki, S. Tsukuda, S. Tagawa, and M. Sugimoto Macromolecules, 39, 7446 (2006).

57. F. S. Kipping, J. Chem. Soc., 125, 2291 (1924).

58. H. Tachibana, Y. Kawabata, S. Koshihara, and Y. Tokura, Solid State Commun., 75, 5 (1990).

59. P. M. Cotts, S. Ferline, G. Dagli, and D. S. Pearson, Macromolecules, 24, 6730 (1991).

60. P. Shukla, P. M. Cotts, R. D. Miller, T. P. Russel, B. A. Smith, G. M. Wallraff, M. Baier, and P. Thiyagarajan, Macromolecules, 24, 5606 (1991).

61. J. R. Koe, M. Fujiki, M. Motonaga, and H. Nakashima, Macromolecules, 34, 1082 (2001).

62. P. M. Cotts, R. D. Miller, and R. Sooriyakumaran, in "Silicon Based Polymer Science," Chapter 23, p 397.

63. J. R. Koe, D. R. Powell, J. J. Buffy, S. Hayase, and R. West, Angew. Chem., Int. Ed., 37, 1441 (1998).

64. M. Schreiber and S. Abe, Synth. Met., 55-57, 50 (1993).

65. L. P. Candeias, J. Wildeman, G. Hadziioannou, and J. M. Warman, J. Phys. Chem. B, 104, 8366 (2000).

66. S. Seki, Y. Kunimi, K. Nishida, K. Aramaki, and S. Tagawa, J. Organomet. Chem., 611, 62 (2000).

67. M. J. Rice and S. R. Phillpot, Am. Phys. Soc., 58, 937 (1987).

68. M. A. Abkowitz, M. J. Rice, and M. Stolka, Philos. Mag. B, 61, 25 (1990).

69. T. Ichikawa, Y. Yamada, J. Kumagai, and M. Fujiki, Chem. Phys. Lett., 306, 275 (1999).

70. T. Ichikawa, M. Sumita, and J. Kumagai, Chem. Phys. Lett., 307, 81 (1999).

71. C. G. Pitt, in "Homoatomic Rings, Chains, and Macromolecules of Main Group Elements," A. L. Rheingold, Ed., Elsevier, Amsterdam, 1977.

72. M. Kumada and K. Tamao, Adv. Organomet. Chem., 6, 80 
(1968).

73. W. B. Pollard and G. Lucovsky, Phys. Rev. B: Condens. Matter Mater. Phys., 26, 3172 (1982).

74. D. Gill, J. Jagur-Grodzinsky, and M. Swarc, Trans. Faraday Soc., 60, 1424 (1964).

75. J. Stegman and W. Cronkright, J. Am. Chem. Soc., 92, 6736 (1970).

76. Y. Matsui, K. Nishida, S. Seki, Y. Yoshida, S. Tagawa, K. Yamada, H. Imahori, and A. Sakata, Organometallics, 21, 5144 (2002).

77. Y. Matsui, S. Seki, and S. Tagawa, Chem. Phys. Lett., 357, 346 (2002).

78. F. C. Grozema, R. J. O. M. Hoofman, L. P. Candeias, M. P. de Haas, J. M. Warman, and L. D. A. Siebbeles, J. Phys. Chem. A, 107, 5976 (2003).
79. H. Bässler, Phys. Status Solidi B, 175, 15 (1993).

80. K. Maeda, S. Seki, S. Tagawa, and H. Shibata, Radiat. Phys. Chem., 60, 461 (2001).

81. A. Charlesby, Proc. R. Soc. London, Ser. A, 222, 60 (1954).

82. A. Charlesby and S. H. Pinner, Proc. R. Soc. London, Ser. A, 249, 367 (1959).

83. O. Saito, J. Phys. Soc. Jpn., 13, 1451 (1958).

84. M. Inokuti, J. Chem. Phys., 33, 1607 (1960).

85. K. Olejniczak, J. Rosiak, and A. Charlesby, Radiat. Phys. Chem., 37, 499 (1991).

86. S. Seki, S. Tagawa, K. Ishigure, K. R. Cromack, and A. D. Trifunac, Radiat. Phys. Chem., 47, 217 (1996).

87. H. Yamakawa, F. Abe, and Y. Einaga, Macromolecules, 27, 5704 (1994).

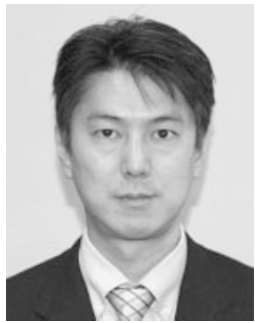

Shu Seki was born in Osaka, Japan in 1968. He received his B.A. and M.A. from the University of Tokyo in 1991 and 1993, respectively. He was selected to a JSPS research fellow in 1993, and was appointed as a Research Associate in the laboratory of Prof. S. Tagawa, The Institute of Scientific and Industrial Research, Osaka University. He received Ph.D in 2001 from Osaka University under supervision of Prof. Tagawa. In 2001, he joined the group of Prof. J. M. Warman at Delft University of Technology, the Netherland. In 2002, he was appointed as an Associate Professor at Osaka University. He received several awards including SPSJ Hitachi Chemical Award (2006), Japan Society of Radiation Chemistry Scientific Award (2000). His research interests include electronic properties and reaction mechanisms of conjugated polymeric materials.

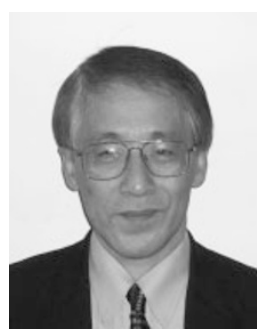

Seiichi Tagawa was born in Shimane, Japan in 1945. He received his Ph.D. in 1977 from the University of Tokyo under supervision of Prof. Y. Tabata. In 1993, he was appointed as a professor of the Institute of Scientific and Industrial Research, Osaka University, and from 2004 to 2006, he was appointed as a deputy director of the institute. He received several awards including Japan Society of Radiation Chemistry Scientific Award (1993), Atomic Energy Society of Japan Award (2002). His research interests include ultra-fast reaction mechanisms and LET effects in polymeric materials and their application to micro- and nano-lithography techniques. 